\title{
Projected changes in the physical climate of the Gulf Coast and Caribbean
}

\author{
Michela Biasutti • Adam H. Sobel • \\ Suzana J. Camargo • Timothy T. Creyts
}

Received: 12 July 2010 / Accepted: 10 September 2011 / Published online: 8 October 2011

(C) Springer Science+Business Media B.V. 2011

\begin{abstract}
As the global climate warms due to increasing greenhouse gases, the regional climate of the Gulf of Mexico and Caribbean region will also change. This study presents the latest estimates of the expected changes in temperature, precipitation, tropical cyclone activity, and sea level. Changes in temperature and precipitation are derived from climate model simulations produced for the Fourth Assessment Report of the Intergovernmental Panel on Climate Change (IPCC AR4), by comparing projections for the mid- and late-21st century to the late 20th century and assuming a "middle-of-the-road" scenario for future greenhouse gas emissions. Regional simulations from the North America Regional Climate Change Program (NARCCAP) are used to corroborate the IPCC AR4 rainfall projections over the US portion of the domain. Changes in tropical cyclones and sea level are more uncertain, and our understanding of these variables has changed more since IPCC AR4 than in the case of temperature and precipitation. For these quantities, the current state of knowledge is described based on the recent peer-reviewed literature.
\end{abstract}

\section{Introduction}

The nations of the Gulf Coast and Caribbean lie in the region comprised by the Gulf of Mexico, Caribbean Sea, and the tropical portion of the western Atlantic ocean; the coastal portions of the North, Central, and South American land masses that enclose them on three sides; and the Caribbean islands. This is a low-latitude region of the

M. Biasutti (凶) · A. H. Sobel · S. J. Camargo · T. T. Creyts

Lamont-Doherty Earth Observatory of Columbia University, Palisades, NY 10964, USA

e-mail: biasutti@ldeo.columbia.edu

A. H. Sobel

Departments of Applied Physics and Applied Mathematics \& Earth and Environmental Sciences, Columbia University, Palisades, NY 10964, USA 
earth, whose proximity to the equator and maritime geography render its climate generally warm and humid.

Rainfall is present throughout the year, evenly distributed between the seasons in the Gulf region but more concentrated during the summer and fall rainy season in the Caribbean, and nearly the whole region is threatened (to varying degrees) by hurricanes during the months between May and October. Yet much of the region lies in the subtropical latitudes which, elsewhere on the earth, feature deserts, and parts of the Gulf Coast and Caribbean region can also be threatened by drought.

As the global climate changes, the regional climate of the Gulf Coast and Caribbean will change as well. Some of the ways in which it will change are fairly certain, while others are much less so. We cannot predict with precision all the ways in which the nations, people, and economies of the region will be harmed (or will benefit) from climate change. Some of the vulnerabilities are clear, however.

In a region that is already warm, increases in temperature-accompanied almost inevitably by increases in specific humidity-may constitute the most obvious and predictable hazard. Precipitation is a more subtle matter, predicted to increase in some places and decrease in others, and in any case predicted with less certainty than temperature. Whether an increase or a decrease in precipitation is considered harmful or beneficial may also vary across the region. Hurricanes may be the most feared hazard in the present climate. How they will change as the climate warms is relatively uncertain, but very focused research from the last several years suggests they will be fewer, but more intense. Sea level rise is a major threat to this region of coasts and islands, both on its own and when coupled with hurricane-induced storm surge; it is inexorable, but the speed with which it will occur is very difficult to predict, depending not only on the rate of global warming but also on the subtle dynamics of polar ice sheets far away.

In this paper, we review the most recent state of knowledge about what changes in climate are expected in the Gulf Coast and Caribbean. We focus on temperature, precipitation, hurricanes, and sea level. We do not attempt to characterize what the impacts of these changes will be, instead limiting ourselves to a discussion of the physical climate alone. We do describe the changes in terms that we expect to be relevant to a variety of societal impacts.

Some regional assessment reports based on the same climate simulations have been produced, e.g., for the US (Karl et al. 2009) or the Caribbean (Bueno et al. 2008). Our treatment here differs in focusing on the Gulf coast and Caribbean together, in our focus on the projected physical changes (as opposed to on recent climatic trends or on the economic impact of future climatic trends), in our use of regional simulations, and in our treatment of tropical cyclones and sea level, and perhaps in some other aspects of our interpretation. The essential elements of our discussion are, however, consistent with the broad scientific consensus reflected in IPCC AR4, particularly regarding temperature and precipitation.

\section{Data and methodology}

For temperature and precipitation, we make use of the global climate model simulations performed under the Third Coupled Model Intercomparison Project (CMIP3; Meehl et al. 2007) for the purpose of the Fourth Assessment Report (AR4; IPCC 
2007) of the Intergovernmental Panel on Climate Change (IPCC). These simulations, and the models used to produce them, are described in greater detail in IPCC AR4 (and the peer-reviewed literature on which that report is based). For the US, we supplement the AR4 simulations with more recent high-resolution (about a third of a degree) regional simulations from the North America Regional Climate Change Assessment Program (NARCCAP). In these simulations, different regional models are integrated with boundary conditions provided from coupled models from the IPCC AR4 archives; at this time, four such simulations are available, using a combination of three regional and three global models. More information on the NARCCAP simulations can be found here: http://www.narccap.ucar.edu/about/index.html.

The large set of global climate model simulations done for IPCC offers the best scientific basis we have for making detailed projections about how climate will change in a specific region. They are not predictions, but scenarios, contingent on assumptions about how anthropogenic emissions of greenhouse gases, as well as other factors which are external to the climate system but which influence it, will evolve in the future. It is virtually certain that anthropogenic emissions of greenhouse gases have been warming the global climate for some time and will continue to do so (most likely at a greater rate) in the future. The precise rate of warming we expect in the future is somewhat more uncertain. One source of uncertainty is our incomplete understanding of the climate system, as manifest by the fact that different climate models project different rates of global mean warming even for the same increases in greenhouse gas concentrations. Another-probably greater-source of uncertainty is that due to our uncertainty about future greenhouse gas emissions. This results from our inability to predict economic and political developments rather than the physics of the climate system.
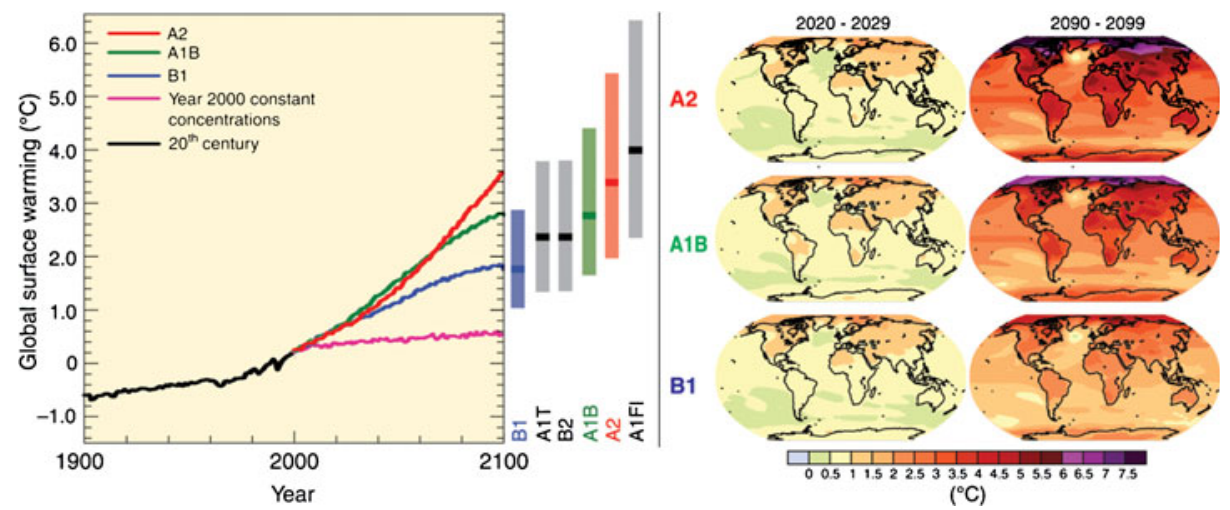

Fig. 1 Global surface temperature changes in multi-model projections from IPCC (2007); the figure and description are taken from that report. Left panel: Solid lines are multi-model global averages of surface warming (relative to 1980-1999) for scenarios A2, A1B and B1, shown as continuations of the 20th century simulations. The magenta line is for the experiment where concentrations were held constant at year 2000 values. The bars in the middle of the figure indicate the best estimate (solid line within each bar) and the likely range assessed for the six SRES marker scenarios at 2090-2099 relative to 1980-1999. Right panels: Projected surface temperature changes for the early and late 21st century relative to the period 1980-1999. The panels show the multi-AOGCM average projections for the A2 (top), A1B (middle) and B1 (bottom) SRES scenarios averaged over decades 2020-2029 (left) and 2090-2099 (right) 
In this report we use results from the A1B scenario of the IPCC AR4. This is considered a "middle-of-the-road" scenario, neither worst-case nor best-case (see Fig. 1). It is possible (though it seems unlikely in the short term) that reductions in emissions will cause the rate at which greenhouse gases increase to be less than that in $\mathrm{A} 1 \mathrm{~B}$, leading to less warming. It is also quite possible that the increases in greenhouse gases will be significantly more rapid than in $\mathrm{A} 1 \mathrm{~B}$, leading to faster warming than that in the A1B projections. Many (though not all) of the results are to some degree linearly proportional to the global mean surface temperature change: if the rate of global warming is less or greater than that in A1B by some factor, the change in local temperature or precipitation in the $\mathrm{A} 1 \mathrm{~B}$ projections is also likely to be less or greater by a similar factor.

The changes we show are computed by averaging the physical quantity (e.g., temperature, precipitation) for a future period in the A1B projections, and subtracting the same quantity averaged over a period of the same duration in the 20 th century. ${ }^{1}$ We subtract the 20th century average values as computed by the models, rather than the observed values, so that any imperfections in the models' representations of the past climate ${ }^{2}$ are not misinterpreted as projections of climate changes.

All results we present are multi-model ensemble means, or averages over the large set of model simulations, using 24 different climate models, ${ }^{3}$ submitted to the IPCC for the A1B scenario. Ensemble averaging is the most straightforward way to handle the uncertainties in both the global climate sensitivity and the ways in which global climate change will be manifest differently in different regions. Some models predict greater changes (both globally and regionally) than the ensemble mean, while some predict smaller ones. The degree to which different models agree on specific aspects of the projected climate change is one measure of our confidence in the likelihood that that specific change will occur in response to increasing greenhouse gas concentrations. If different models differ widely, our confidence is low. If most or all of them agree closely, we are still not entirely certain that they are correct (because the models are not perfect representations of the real climate system), but our confidence is substantially greater.

Tropical cyclones and sea level are important facets of climate for the Gulf Coast and Caribbean. The combination of the two-rising sea level leading to greater flooding from storm surge when hurricanes make landfall-is potentially one of the

\footnotetext{
${ }^{1}$ Due to the variations in the availability of data, slightly different periods are used for the computation of some different statistics. For time-averaged fields, the period 2075-2099 is compared to 1975-1999. For extremes (Figs. 3, 4, 8 and 9) the normals are defined over 30 years, so those are compared to 30-year averages for the models, 2020-2049 and 2070-2099. The NARCCAP 21st century simulations are forced with a more aggressive scenario (A2), but are run for an earlier period: 2040-2070. In the paper we will label the reference period in the simulation of the 20th Century as $20 \mathrm{C}$ and the simulations of the 21 st century as $21 \mathrm{C}$, regardless of the scenario used.

${ }^{2}$ The CMIP3 models reproduce the seasonal evolution of temperature and rainfall fairly well, but fail to capture some regional detail. For example, they simulate colder than observed surface temperature in the Caribbean sea, especially in spring and summer, which leads to less rainfall over the Islands in the early rainy season (Rauscher et al. 2008). The coarse resolution prevents a faithful simulation of orographic features, such as maxima in rainfall along the Caribbean coast of Central America and the cold summertime temperatures over the Sierra.

${ }^{3}$ For extremes, as shown in Figs. 3, 4, 8 and 9, data were not available for all models; results shown are computed from the nine models for which these data were available.
} 
most serious long-term risks for the region. Unfortunately, current climate models, such as those from the CMIP3 ensemble from which we derive projections of temperature and precipitation change, are not up to the task of making quantitative projections of regional changes in either tropical cyclones or sea level. In the case of tropical cyclones, the coarse grid resolution of the models prevents the models from simulating tropical cyclones adequately even in the present climate; thus changes in tropical cyclones in model projections of the future are not reliable. In the case of sea level, any projection depends critically on the dynamics of ice sheets on land, something not yet simulated well (or not simulated at all) by the models. Thus, our discussions of tropical cyclones and sea level are not based directly on climate model projections of these quantities. Rather, we summarize results from the recent literature, including that written after IPCC AR4. Both topics are subjects of intense research, and understanding of both has evolved considerably even since the release of IPCC AR4 a few years ago. Nonetheless there are still very substantial uncertainties in both these areas and our discussion characterizes that.

In summary, this report presents what current science has to tell us about the risks for the US Gulf coast and the Caribbean under climate change. To quantify this risk, we use climate model-based projections produced for the IPCC AR4, under one particular scenario for increases in greenhouse gases, comparing the projected late-
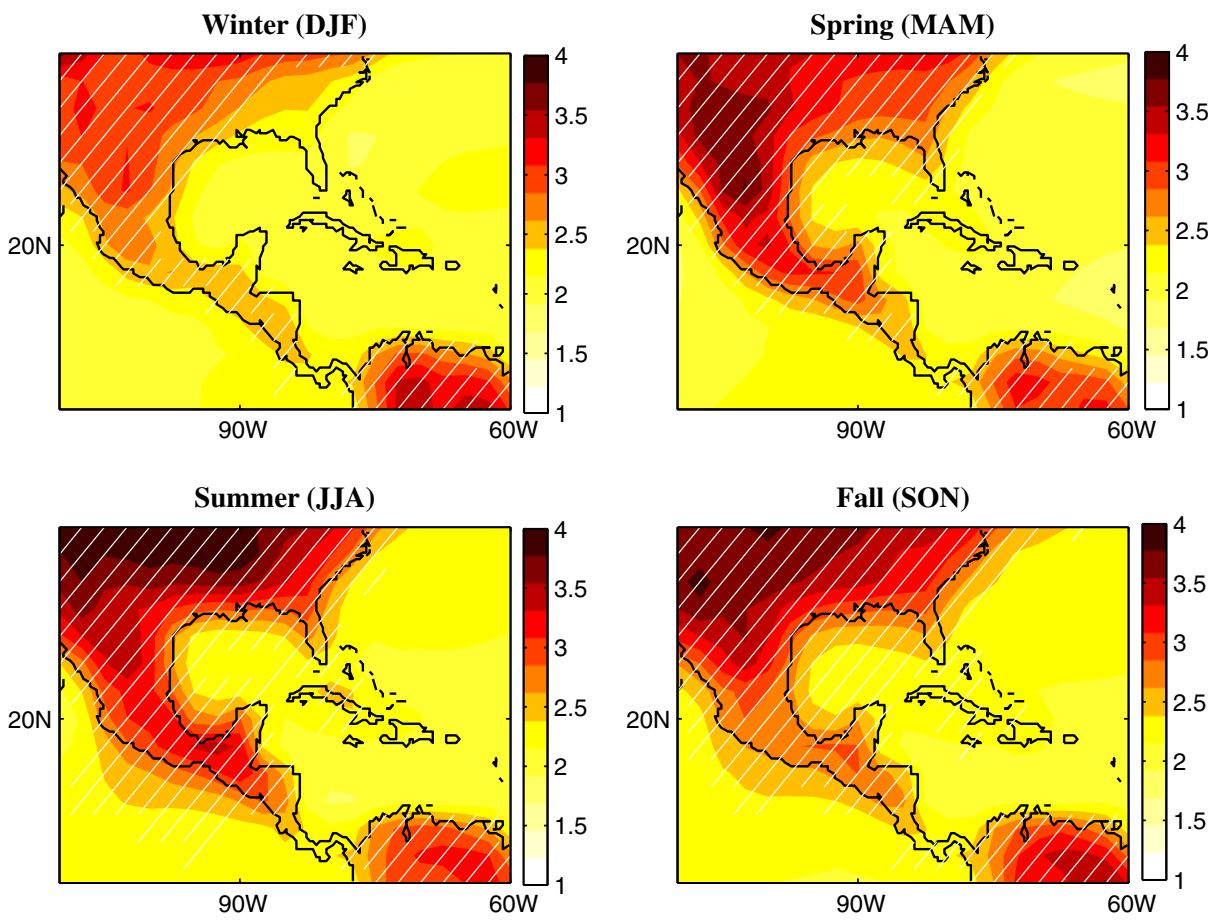

Fig. 2 Multi-Model mean of seasonal temperature anomalies A1B (2075-2099) minus 20C (19751999). The anomalies are positive and statistically significant everywhere for all models. The hatching indicates regions where $75 \%$ of the models agree that warming will be larger than $2^{\circ} \mathrm{C}\left(3.6^{\circ} \mathrm{F}\right)$. The shading interval is $1 / 4^{\circ} \mathrm{C}$ (about half ${ }^{\circ} \mathrm{F}$ ) 
21 st century climate to that in the late 20th century. For the US, we supplement the IPCC simulations with the four NARCCAP simulations, in order to assess if there is qualitative agreement between the coarse-resolution and the fine-resolution models. Because of uncertainty in future greenhouse gas emissions, uncertainties associated with the models' imperfect representations of the climate system, and the different time horizons which may be of interest for different applications, the results below should not be interpreted as precise quantitative predictions. Rather, they should be taken as broadly indicative of the kinds of changes that are likely to occur as the climate warms. Our discussions of changes in tropical cyclones and sea level are, due to the nature of the subject, more qualitative than our discussions of temperature and precipitation, and are based on surveys of the recent peer-reviewed literature rather than directly on the climate model projections from IPCC AR4.

Fig. 3 Average heat wave duration index (HWDI, in days) as simulated by nine climate models. The yearly value of HWDI measures the maximum period (over the course of that year) with maximum temperature more than $5^{\circ} \mathrm{C}$ above the 1961-1990 daily normal, subject to the restriction that such period must be longer than five consecutive days. Top: 1961-1990 average in the 20th century integrations. Middle: 2020-2049 average in the 21C (A1B) integrations. Bottom: 2070-2099 average in the 21C (A1B) integrations. Hatching in the bottom panels indicates areas in the increase with respect to the climate normal is statistically significant at the $95 \%$ level for at least $2 / 3$ of the models. The shading interval is five days
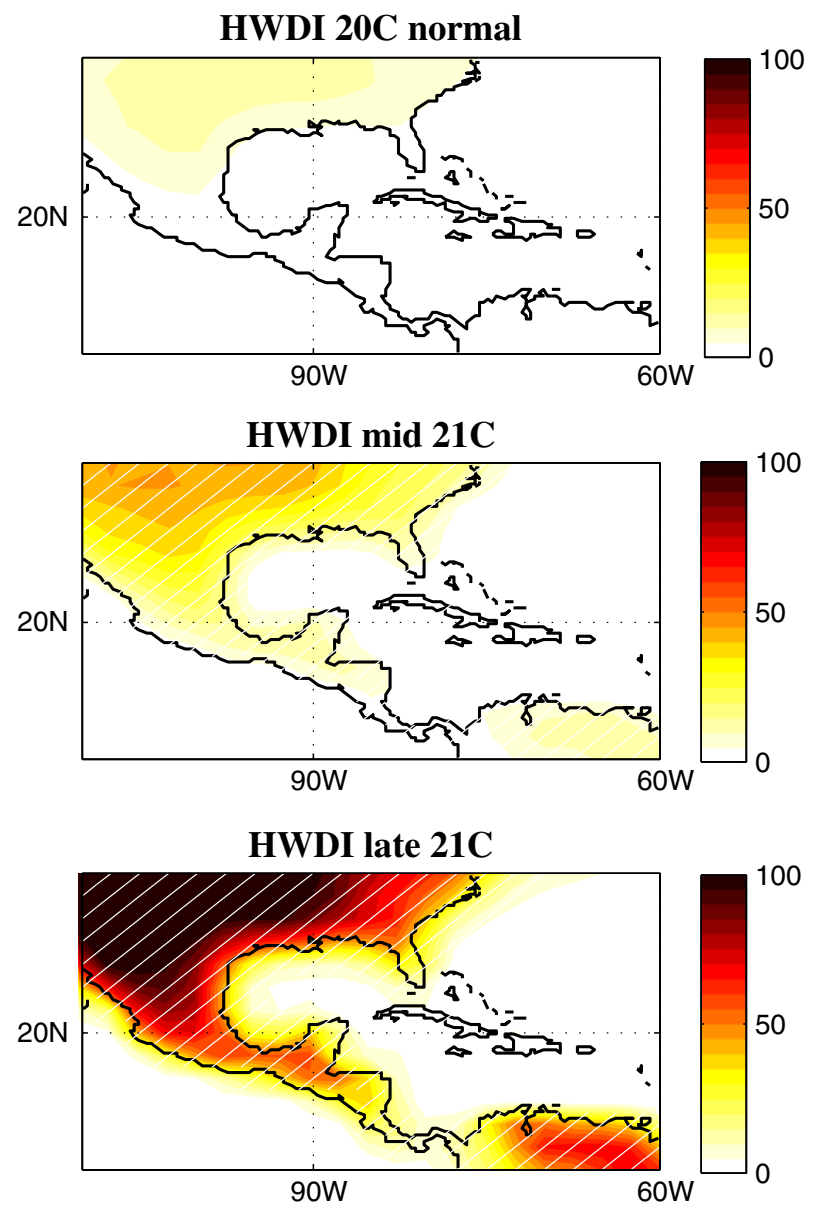


\section{The regional climate}

\subsection{Temperature}

The most robust response to increased greenhouse gases in the Gulf and Caribbean region, as elsewhere, is a marked warming. This is manifest in increases in seasonal mean surface temperature, in the number of warm nights, in record high temperature, in the duration of heat waves, and a corresponding decrease in days below freezing, record lows, and cold snaps.

Figure 2 shows the differences, or "anomalies" in seasonal mean surface air temperature between the late 21st century and the late 20th century. As discussed above, the results from both periods are computed from the ensemble mean of the 24 climate models used in IPCC AR4. The warming is statistically significant everywhere if computed for each model individually, as well as for the ensemble mean. In all seasons, the continent warms more than the ocean, and $75 \%$ of the models project more than $2^{\circ} \mathrm{C}\left(3.6^{\circ} \mathrm{F}\right)$ of mean warming. The details of the warming vary with the seasons. During spring, the maximum warming follows the topography and is likely associated with earlier snow-melt. During summer and fall the landsea contrast is maximum, and the warmest temperatures are in the interior of the continent.

Figure 3 show the maximum duration of a heat wave as simulated by 9 climate models for the 20th century climate normal period (1961-1990), early in the 21st century (2020-2049) and late in the 21st century (2070-2099). Here a heat wave is defined as a period of at least five days when temperatures exceed the normal for

Fig. 4 Average percentage of warm nights as simulated by nine climate models. A warm night is one when the minimum daily temperature is warmer than the 90th percentile of daily minimum temperature during the 1961-1990 climate normal. By definition, the percentage of warm nights during 1961-1990 is $10 \%$; values of $100 \%$ indicate that every night will feel as warm as the warmest $10 \%$ of the recent past for the same time of year. Top: 2020-2049 average in the $21 \mathrm{C}$ (A1B) integrations. Bottom: 2070-2099 average in the $21 \mathrm{C}$ (A1B) integrations. The anomalies are significant everywhere. The shading interval is $5 \%$
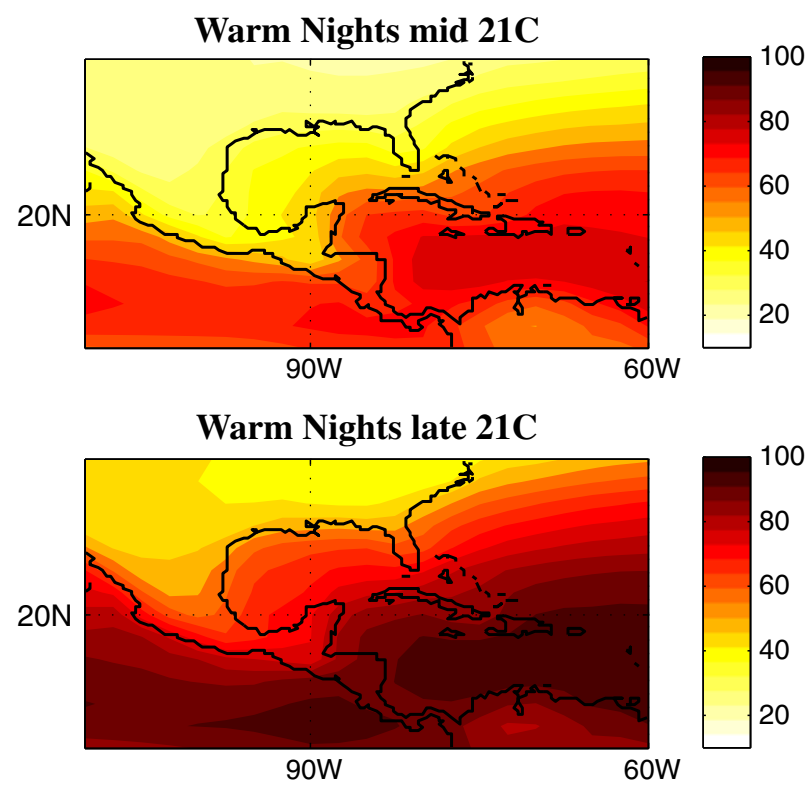
that calendar day by $5^{\circ} \mathrm{C}\left(9^{\circ} \mathrm{F}\right)$. In the US interior, by the end of the century, entire seasons will be as warm as what we now consider a heat wave. The increase is not so dramatic for more maritime regions, but even along the Gulf we can expect "heat waves" of more than two months. This increase in occurrence of heat waves will of course happen gradually, but is expected to be already noticeable in the near future (Diffenbaugh and Ashfaq 2010).

The increase in the number of warm nights (Fig. 4) is also widespread, but is expected to be greater in the deep tropics and Caribbean, less so over the US. Nights as warm as the $10 \%$ warmest nights of a typical year in the $60 \mathrm{~s}, 70 \mathrm{~s}$, or $80 \mathrm{~s}$ will be four times as frequent in the Gulf states (eight times, in Hispaniola) by the end of this century. Warm nights and heat wave duration are both relevant to the visceral human experience of climate, and also likely related to energy use in regions where air conditioning is widespread.
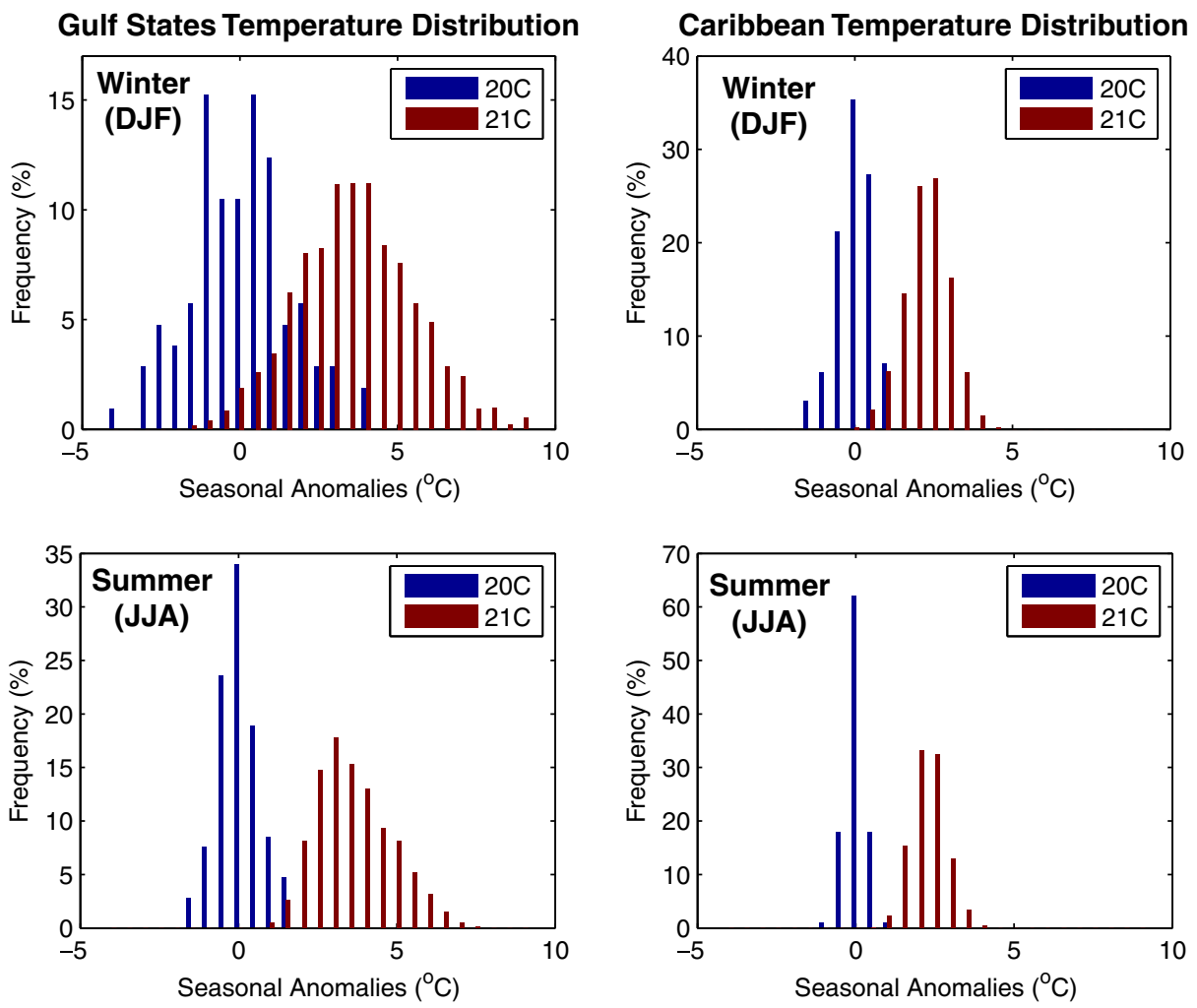

Fig. 5 Frequency distribution of seasonal mean surface temperature anomalies in observations (1900-2005, labeled 20C, in blue) and estimated for the end of the 21st century (labeled 21C, in red). The $21 \mathrm{C}$ distribution is obtained by adding the 20C observed anomalies to the difference 2075-2099 minus 1975-1999 as simulated by each of the 24 models in the CMIP3 archive. The top panels are for winter (DJF) and the bottom panels are for summer (JJA). The left panels are for a box comprising Louisiana, Mississippi and Alabama (95W-85W; 30N-35N), the right panels are for a box centered over the Caribbean $(85 \mathrm{~W}-70 \mathrm{~W} ; 15 \mathrm{~N}-25 \mathrm{~N})$. Observations over the US are from the NOAA NCDC CIRS Climate Division (1900-2005); over the Caribbean they are NOAA NCDC GCPS gridded anomalies derived from the Global Historical Climate Network (1894-1993) 

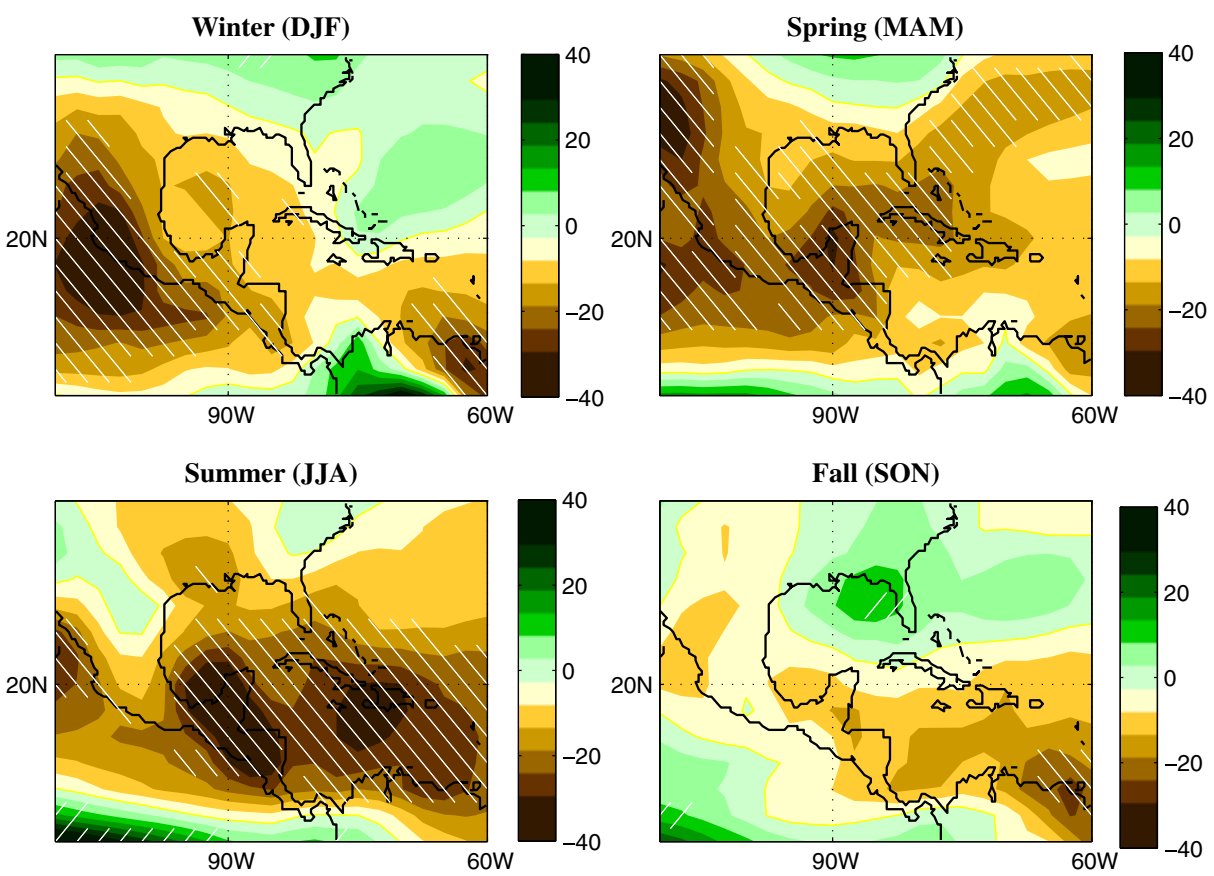

Fig. 6 Multi-model mean of seasonal rainfall anomalies A1B (2075-2099) minus 20C (1975-1999). The hatching indicates regions where $75 \%$ of the models agree on the sign of the anomalies

The temperature increases alone are underestimates of the extent to which it will feel warmer, as humidity will increase as well. Particularly over the oceans and coastal regions (which describes most of the Gulf coast and Caribbean), the models project little change in relative humidity. ${ }^{4}$ This projection-which is also robustly supported by our understanding of the physics of near-surface climate, and by observations of variability in the present climate-means that as temperature increases, there will also be significant increases in specific humidity.

Another way to get a sense for how a mean warming of about $3^{\circ} \mathrm{C}\left(6^{\circ} \mathrm{F}\right)$ feels is to look at the historical anomalies in seasonal mean temperature and ask how an average summer or winter in 2090 will compare to a hot season in the 20th century. Following Battisti and Naylor (2009) we derive the frequency distribution of seasonal temperature anomalies from observations of the 20th century and construct a similar distribution for the 21 st century by adding the $21 \mathrm{C}-20 \mathrm{C}$ changes simulated by the model. Because of scatter in the models' projections, the distribution for the 21 st century is wider than the observed for the 20th century. The results of this computation for winter and summer temperature in the Gulf states and the Caribbean are shown in Fig. 5. In the Gulf, a typical winter in the last decades of this century will be as warm as the warmest winter ever recorded and the coolest summers will be as hot or hotter than any summer in the last century; in $95 \%$ of the

${ }^{4}$ Relative humidity is the ratio between the actual (specific) humidity and the humidity of saturated air at the same temperature. 
years, summer temperatures will be unprecedented. A similar picture emerges for the Caribbean: here the interannual variability is much smaller (reflecting both the tropical location and the maritime climate), making all summers and $90 \%$ of winters at the end of the century warmer than ever in the past.

\subsection{Rainfall}

The mean rainfall response to greenhouse gas increases in the Gulf and Caribbean can be broadly described as a drying of the latitude band between $10^{\circ} \mathrm{N}$ and $30^{\circ} \mathrm{N}$, with wetting to the south and to the north (Fig. 6 and also Fig. 12). Looking more carefully at the seasonal evolution and the spatial detail of the anomalies, we are confronted with much more uncertainty than for the temperature response. In the mean, models project moderate drying along the Gulf coast for most of the year, except the fall, but because the Gulf states are located at the latitude where we expect rainfall anomalies to switch from negative to positive, the outlook is uncertain. We have compared the projections of Fig. 6 with those obtained by four regional projections by the North American Regional Climate Change Assessment Program
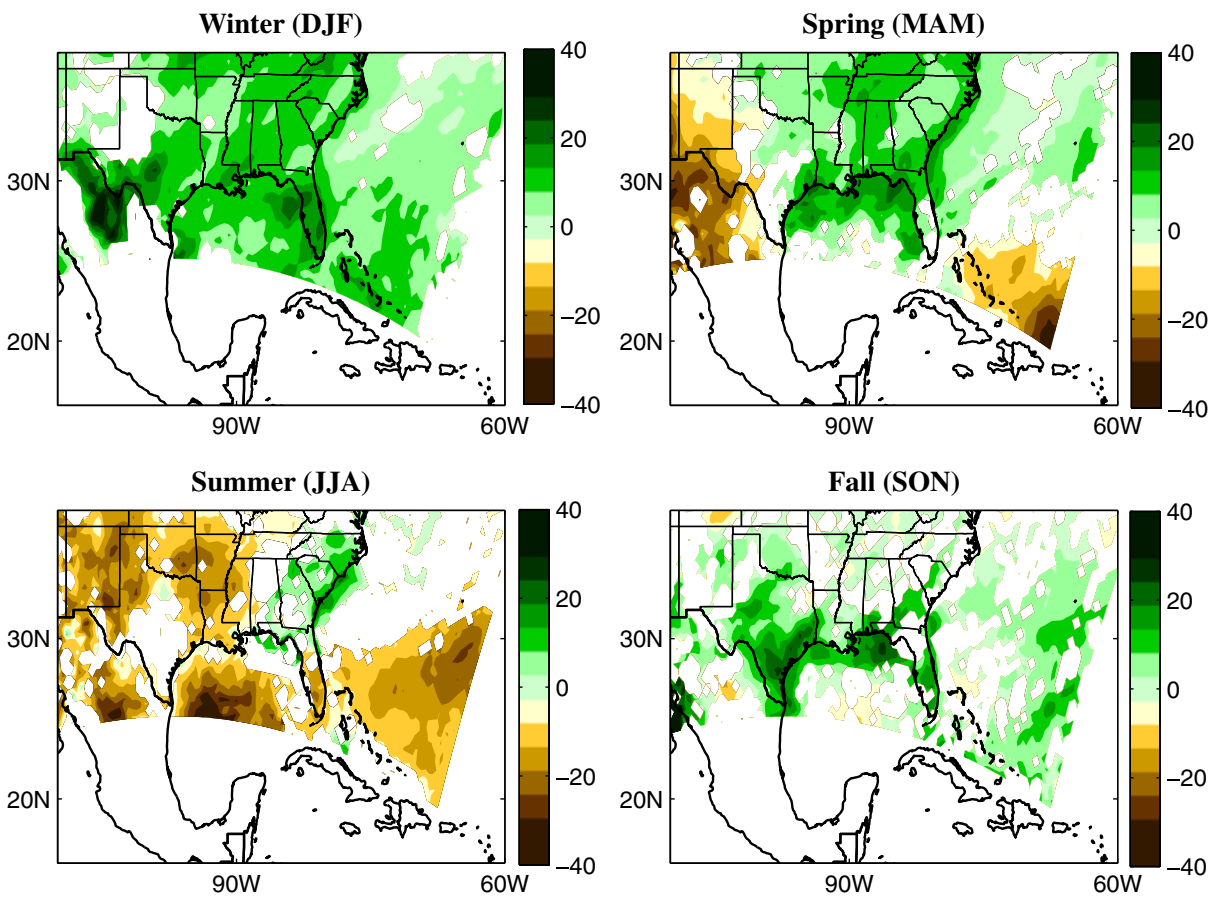

Fig. 7 Mean of seasonal rainfall anomalies in four NARCCAP simulations: A1B (2045-2070) minus 20C (1975-1999), expressed as percentage of the 20C climatology. Only regions where at least three out of four models agreed on the sign of the seasonal anomalies are plotted. The white regions in the south and east are regions not covered by the NARCCAP models; elsewhere white regions indicate a lack of model agreement 
Fig. 8 Top: Observed average maximum number of consecutive dry days (CDD, accumulation less than $1 \mathrm{~mm}$ ) during 1961-1990 calculated from daily gridded data at $1^{\circ} \times 1^{\circ}$ resolution (http://www.cpc.ncep.noaa. gov/products/precip/realtime/ GIS/retro.shtml). White areas indicate regions not covered by this analysis. Middle: Multi-model difference between the 2020-2049 average in the $21 \mathrm{C}$ (A1B) integrations and the 1961-1990 average in the $20 \mathrm{C}$ integrations, expressed in percentage of the 20C normal. Bottom: as in middle, but for 2070-2099. Hatching indicates regions where the multi-model mean anomalies are larger than the scatter (standard deviation) among the models. The shading interval is $8 \%$
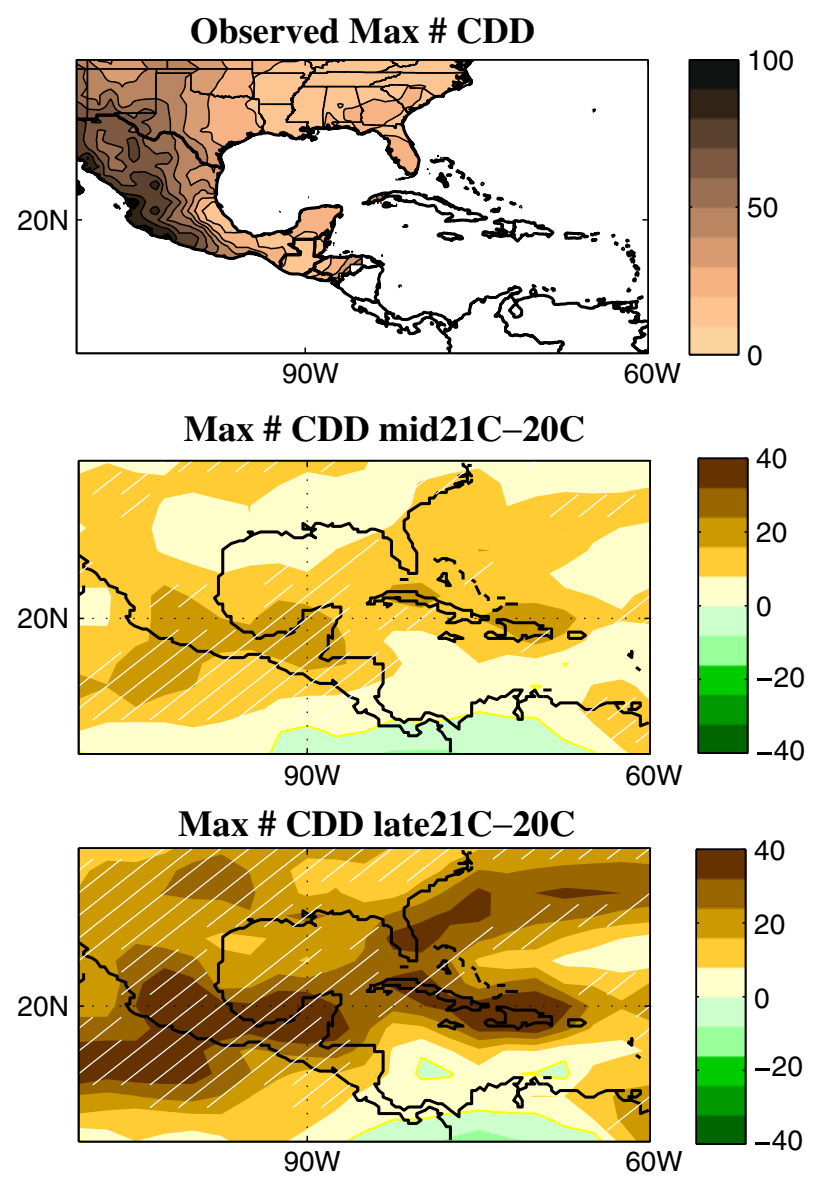

(NARCCAP, ${ }^{5}$ Fig. 7). During winter and spring the two ensembles project anomalies of the opposite sign, a disagreement that underscores the uncertainty of the forecast for these seasons. During summer and fall, the projections of the IPCC models for the Gulf are moderately more significant: more than $75 \%$ of the models project dry anomalies extending over Louisiana and Mississippi in summer and positive anomalies in the northern Gulf Coast in the fall. These projections are also confirmed by the NARCCAP ensemble, which projects more extensive dry anomalies, centered over Arkansas but also covering Louisiana and Mississippi (cf. Figs. 6 and 7). Over the Caribbean we can only rely on the IPCC ensemble, but our certainty is nonetheless greater than for the Gulf, at least in spring and summer for which the models project a very robust $30 \%$ drying (Rauscher et al. 2008).

Analysis of daily data suggests that the character of precipitation will also undergo small changes. The maximum number of consecutive dry days (CDD) over the course of a year is expected to increase, especially over the Caribbean and consistent with a

\footnotetext{
${ }^{5} \mathrm{~A}$ full description of the integrations is available from www.narccap.ucar.edu.
} 
lengthening of the dry season (Fig. 8), while the number of days with rainfall larger than $10 \mathrm{~mm}$ (about 0.4 in, a typical daily rainfall amount in this region, see Fig. 9, top) is projected to decline, especially where summer mean rainfall is projected to decrease (not shown). The average intensity of precipitation is projected to increase slightly over the continent (Fig. 9, middle and bottom). Although these anomalies are not significant, they are consistent with theoretical expectations of stronger convective activity and with a statistically significant increase in very heavy rainfall: Kharin et al. (2007) report that rainfall so heavy that it would be expected to occur only once in 20 years during the late 20th century is expected to return every 10-15 years during 2046-2065. No consistent change in the intensity of rainfall events is projected for the Caribbean.

The regional models (Fig. 10) support the conclusion that the average intensity of precipitation will increase over all the southeastern states, and suggest that the intensification might be largest in close proximity to the Gulf coast. The projected changes in the number of consecutive dry days and the number of heavy rainy days can again be related to the mean summertime rainfall anomalies, which, in the

Fig. 9 As in Fig. 8, but for the simple daily intensity index (SDII), defined as the average rainfall intensity on rainy days (accumulation larger than $1 \mathrm{~mm}$ ) expressed in $\mathrm{mm} /$ day. The shading interval is $0.1 \mathrm{~mm} /$ day
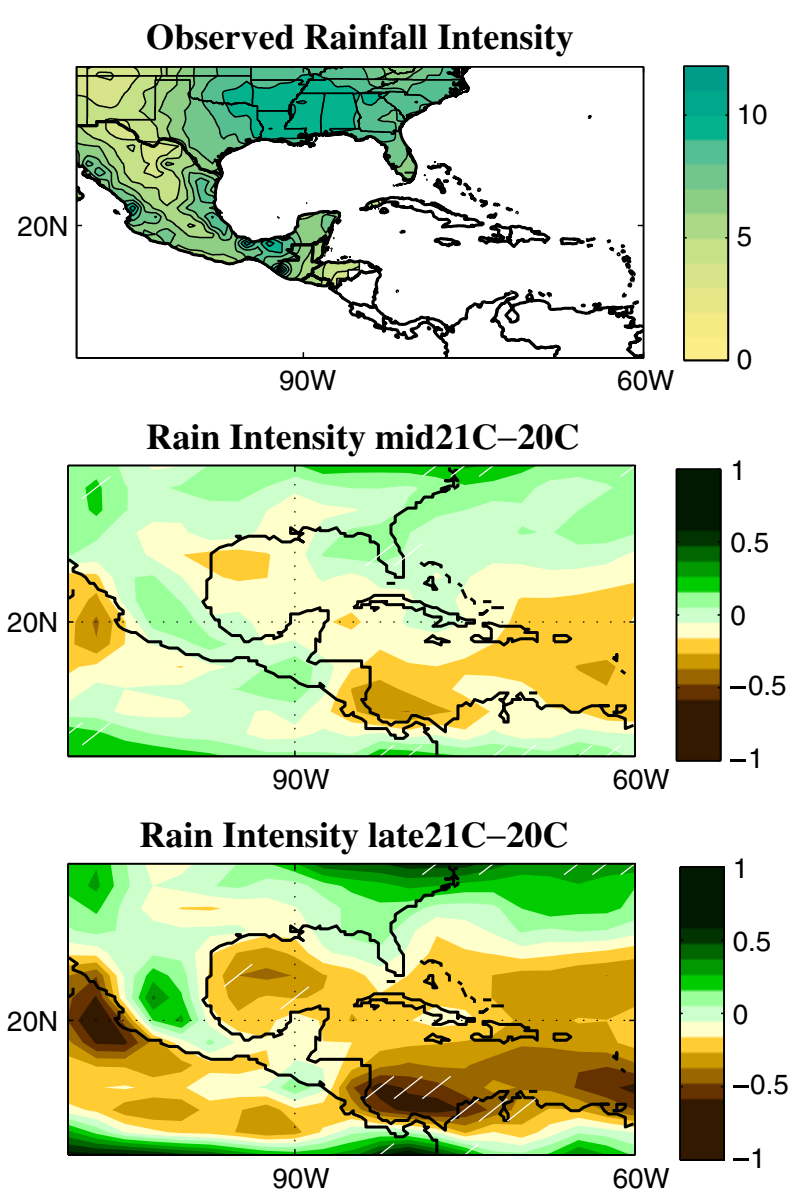
Fig. 10 Mean of annual anomalies in 4 NARCCAP simulations: $21 \mathrm{C}$ (A2 scenario, 2041-2070) minus 20C (1971-2000). Top: Number of consecutive dry days (percent change, shading interval 6\%). Middle: Number of days with rainfall total exceeding $10 \mathrm{~mm}$ (percent change, shading interval is $3 \%$ ). Bottom: Average rainfall intensity on rainy days (rain $>1 \mathrm{~mm}$ ) expressed in mm/day (shading interval $0.3 \mathrm{~mm} /$ day). Only regions where at least three out of four models agreed on the sign of the seasonal anomalies are plotted. The white regions in the south and east are regions not covered by the NARCCAP models; elsewhere white regions indicate a lack of model agreement
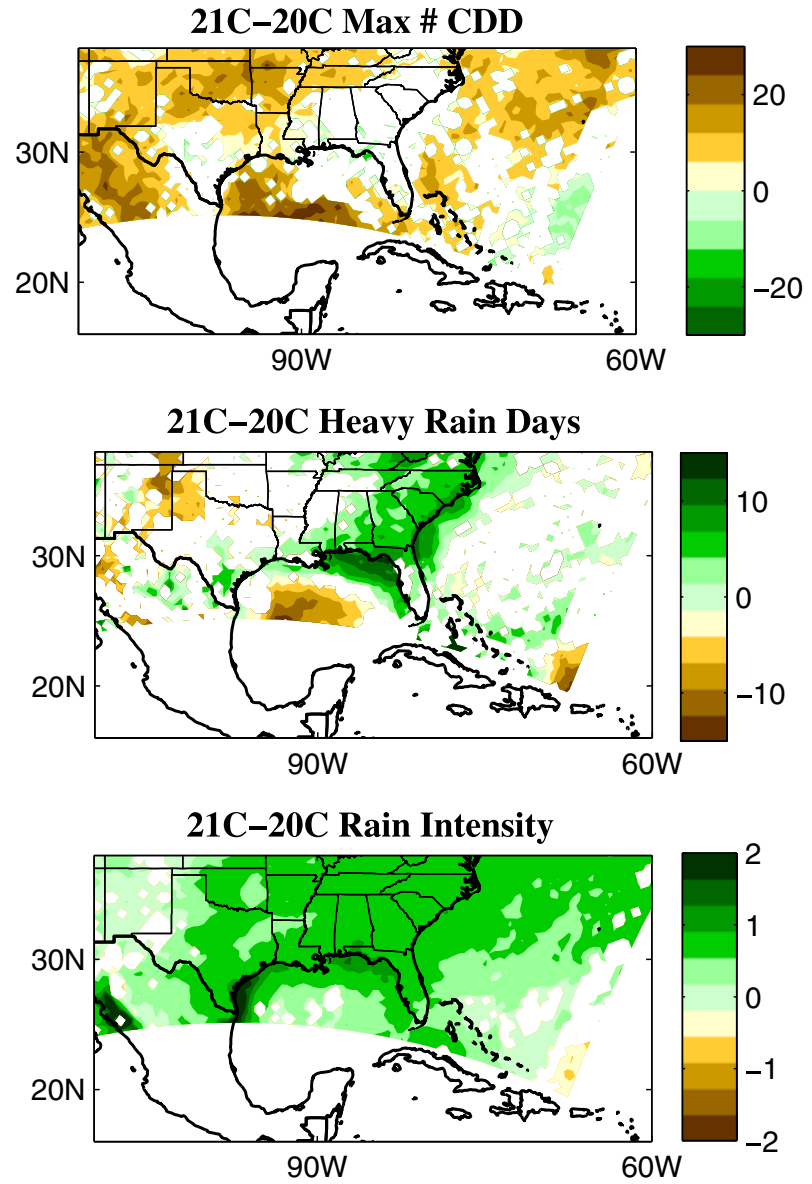

regional models, showed dry anomalies in the west of Mississippi and wet anomalies to the east. The maximum dry spell lengthens to the west, and is uncertain to the east. The number of days with rainfall exceeding $10 \mathrm{~mm} /$ day increases in the east and is uncertain elsewhere. This pattern of anomalies supports the idea that changes in warm weather convection are responsible for the changes in precipitation extremes.

Figure 11 shows 20th and 21st century frequency distributions for seasonal precipitation, analogously to Fig. 5. We see that the much larger observed variability and the more modest mean change in rainfall projected for the 21st century combine to give similar frequency distributions over the past and the future. Although the record driest seasons will be unprecedentedly dry, seasonal mean precipitation in most years will be within the historical range. This does not mean that hydrological droughts - shortages of water in soils, reservoirs, lakes and streams-will not become more frequent or more severe than in the past, in the Caribbean in particular. Severe hydrologic drought tends to result from a long sequence of many years in which precipitation is less than normal, rather than from just one very dry year. The projected shift in the frequency distribution of seasonal precipitation in the 

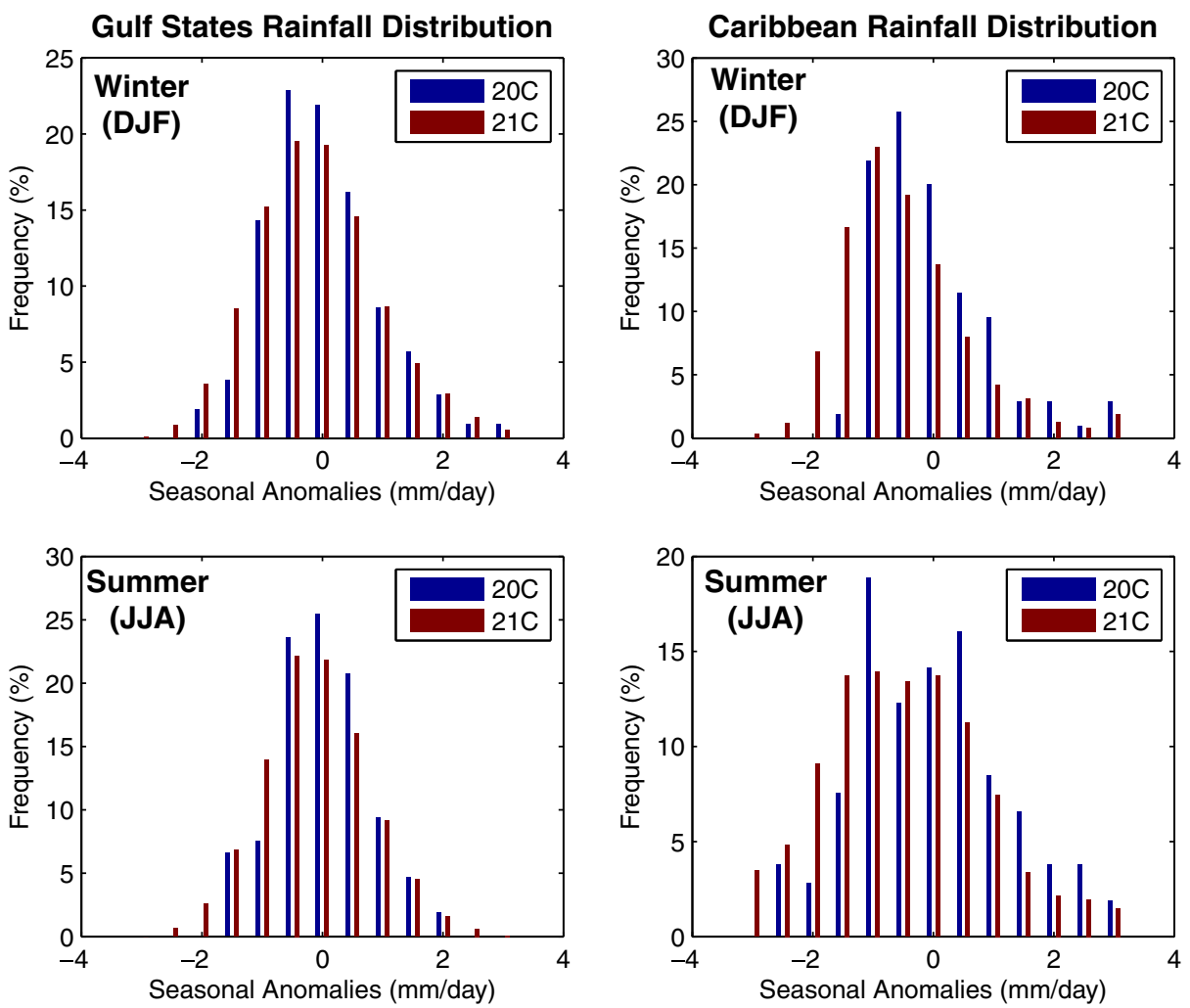

Fig. 11 As in Fig. 5, but for seasonal precipitation. Observations for the 20th century are from the Global Historical Climatology Network (http://www.ncdc.noaa.gov/oa/climate/ghcnmonthly/index.php)

Caribbean suggests that the likelihood of multiple dry years in sequence will increase there.

\subsection{The physical basis}

To place the Gulf and Caribbean in the context of broader regional-scale changes, we expand our outlook to include the tropical band from Africa to the East Pacific. In Fig. 12 we show the 21C-20C anomalies in annual mean sea surface temperature (SST) and rainfall. The surface ocean warming in the Atlantic is not uniform, but has a clear spatial structure that is very robust across the models (Leloup and Clement 2009; Xie et al. 2010). The warming has a relative minimum in a southwest-northeast band from the Caribbean to North Africa and Spain. Greater warming is found to the south and north of this band, in the region of the "Intertropical Convergence Zone" between northeast Brazil and West Africa, and over the northwest tropical Atlantic. A strong local maximum in surface ocean warming is also found in the equatorial eastern Pacific; in this respect the future climate is projected to bear some resemblance to an El Niño event (Philander 1990; Sarachik and Cane 2010) in the present climate. This too is a robust response of the models, with a clear physical 
21C-20C $\mathrm{T}_{\text {sfc }}$ and Rainfall Anomalies

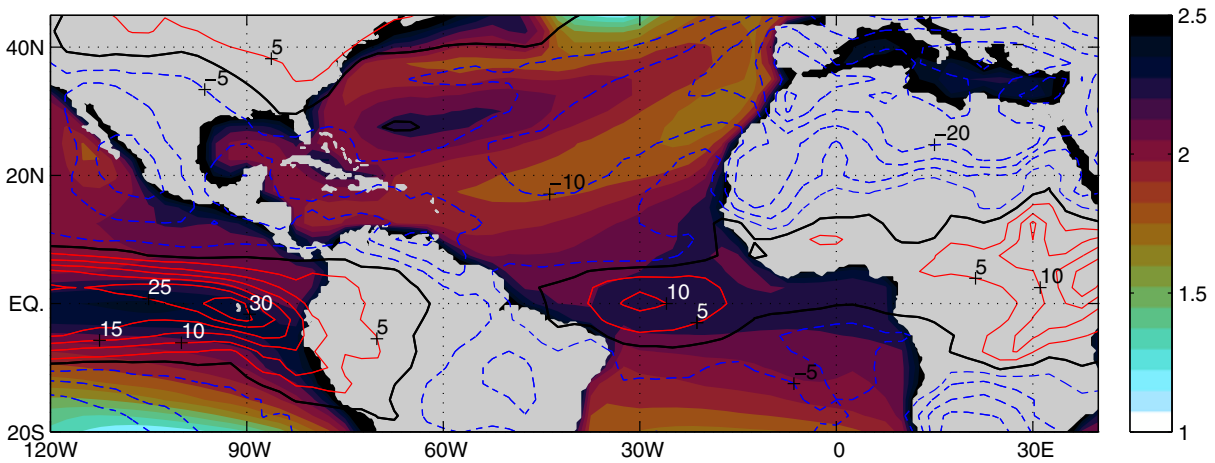

Fig. 12 Multi-model mean of the difference between 21C (2075-2099) and 20C (1975-1999) in annual mean sea surface temperature (shaded, shading interval is $0.1^{\circ} \mathrm{C}$ ) and rainfall (contours, in percentage of 20C values; red solid contours indicate wet anomalies, dashed blue contours indicate dry anomalies)

interpretation involving the weakening of the tropical atmospheric circulation in response to warming (Vecchi et al. 2006; DiNezio et al. 2009).

It is clear from the correspondence between the spatial patterns of precipitation change and SST change that the two are related. Precipitation is projected to increase strongly over the near-equatorial regions of the east Pacific and Atlantic in which SST rises the most, and to decrease over the band of minimum increase, which includes most of the Caribbean and Gulf. In the current tropical climate, there is a close and well-known correspondence between spatial variations in SST and precipitation, with greater precipitation, on average, over regions of higher SST. The relevant quantity for precipitation is not absolute SST, but relative SST, that is, the difference between the local SST and the average over the rest of the tropics; this controls the stability of the atmospheric column, thus the tendency for deep convection (tropical rainstorms), and thus also the atmospheric circulation which moves atmospheric moisture from some regions to others, causing rainfall to be much more variable than surface evaporation (e.g., Sobel 2007). If SST were uniform in space, any warming would be expected to lead to a modest increase in precipitation, on the order of $2 \%$ per degree of surface warming (e.g., Held and Soden 2006). The regional changes shown in Fig. 12 are considerably different, and in many places larger than this, clearly due to relative SST changes (Rauscher et al. 2010). The drying of the Caribbean shown in the preceding figures is thus part of a coherent, large-scale pattern of regional climate change that is manifest in multiple variables and that can be understood in the context of mechanisms operating in the present climate.

\section{Tropical cyclones}

The risk of societal harm from tropical cyclones (TCs) is a function not only of the storms themselves, but also of a variety of physical and societal factors. These other factors are likely to change as much or more than the storms themselves. For example, rising sea level increases the risk associated with storm surges, while 
increasing coastal development increases economic damage for a given storm. To provide a baseline for considering these issues, we first briefly describe the present climatology of tropical cyclones in the Gulf and Caribbean, before continuing to discuss the current state of the science regarding how tropical cyclones in this region may change in the future as the climate warms.

\subsection{Present climatology}

Figure 13 shows the tracks of all 418 Gulf of Mexico-Caribbean TCs (defined here as those reaching tropical storm strength or greater and passing through a box bounded by latitudes $8 \mathrm{~N}-31 \mathrm{~N}$ and longitudes $100 \mathrm{~W}-60 \mathrm{~W}$ ) which occurred in in the period 1950-2009. The greatest hurricane activity occurs in the period from August to October, with a maximum in September (not shown). The number of storms each year in the region since 1950 is shown in Fig. 14.

Gulf and Caribbean storms comprise $71 \%$ of all TCs in the period 1851-2009 in the North Atlantic basin. Given this majority, as well as the fact that most research on future tropical cyclone changes considers entire basins rather than smaller sub-regions, we describe below the results from recent research on North Atlantic variability as a whole. It is reasonable to assume that if TC activity increases or decreases basin-wide, similar increases or decreases will occur in the Gulf and Caribbean, on average.

\subsection{Trends and future changes}

Our ability to make projections of changes in TC activity as the climate changes derives from several sources of information: analysis of historical variations in observed TC activity leading up to the present; simulation with computer models; and our understanding of the physics of tropical cyclones, which provides some insight into the expected relationships between large-scale climate changes (such as those shown above in Section 3) and TC activity.

\subsubsection{Observational evidence}

In the north Atlantic, in the decades since the 1970s (the best observed region and time period in the global TC record) there has been an increasing trend in the number of intense storms (Webster et al. 2005), as well as in the power dissipation index (PDI), a measure which combines the number, intensity, and lifetime of all storms in a season (Emanuel 2005). These recent Atlantic trends (visible by eye in Fig. 14, if one focuses on the last few decades) appear real, as opposed to being artifacts of inadequate data sets. They remain present when a homogeneous data set based only on satellite observations is used (Kossin et al. 2007; Elsner et al. 2008), as opposed to the possibly inhomogeneous "best track" data sets, produced using a variety of different types of observations, used by the earlier studies. It is more difficult to say whether these trends have an anthropogenic component, or are simply a natural upswing following earlier decreases, part of a multi-decadal oscillation that is inherent to the Atlantic climate system (Goldenberg et al. 2001). The argument for an anthropogenic component involves a possible role for aerosols (Evan et al. 2009) as well as greenhouse gases (Mann and Emanuel 2006). It is quite possible that both anthropogenic and natural mechanisms are contributing (Ting et al. 2009). 
Fig. 13 Tracks of all tropical cyclones which entered the Gulf of Mexico-Caribbean region (shown in the box) during the period 1950-2009. Colors arbitrary, varied to make it easier to distinguish the curves

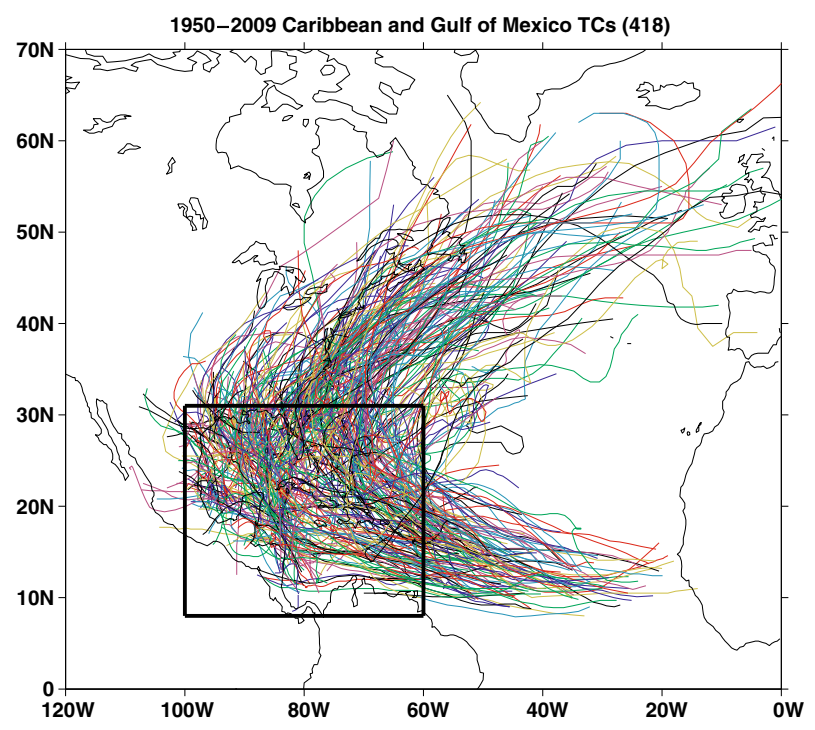

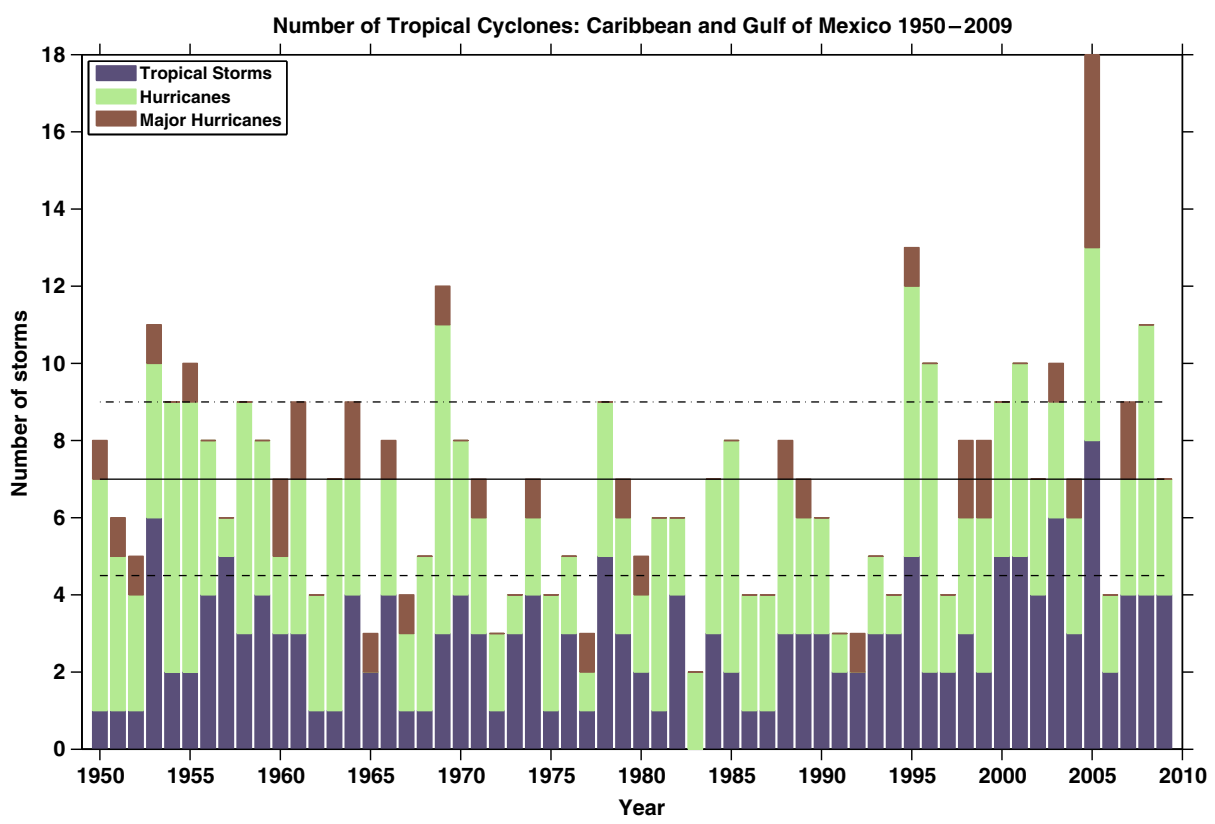

Fig. 14 Total number of tropical storms, hurricanes and major hurricanes (categories 3-5) per year in the Gulf of Mexico-Caribbean region (1950-2009). The mean number of TCs is shown by the black continuous line. Colors indicate the number of storms whose maximum intensity was tropical storm, hurricane (categories 1 and 2) or major hurricane (categories 3-5). The top (bottom) broken line shows the 75th (25th) percentile of the the distribution of total storm number over the whole record 
One approach to quantify the anthropogenic trend would be to look at the entire data record since the mid-19th century: presumably trends over this longer period would be more likely to be anthropogenic in origin than would shorter-term trends. Unfortunately, attempts to identify trends over these longer periods are rendered inconclusive by the greater inhomogeneity of the data in the early record (Landsea 2005, 2007; Landsea et al. 2006). It is quite possible that storms occurring at sea could have gone unobserved in the 19th or early 20th centuries. In more recent years this is less likely due to increased ship traffic and, since 1970, satellites. These changes in observational capacity may be expected to introduce an artificial upward trend, potentially as large as those actually found in the data (Chang and Guo 2007; Mann et al. 2007; Vecchi and Knutson 2008; Landsea et al. 2010).

\subsubsection{Influence of SST and other environmental changes}

We can use our physical understanding of the mechanisms by which specific aspects of the climate influence the formation and intensification of TCs, together with historical relationships between TC formation and intensification and climate at interannual time scales, to inform our expectations of the response of TC activities to a given change in climate. Tropical cyclones form only in regions of relatively high sea surface temperature (SST). SST has long been recognized as one of the factors that influences both TC formation (Gray 1979) and the maximum intensity attainable by a mature TC (Emanuel 1987; Holland 1997). This relationship has spurred the concern that future SST increases in response to increased greenhouse gases will be associated with increases in the number and intensity of TCs. Yet, much of the observed relationship between SST and TC activity in the historical record can be explained as well or better by relative SST - the difference between the local SST at a given location and the tropical mean-than by absolute SST (Vecchi and Soden 2007b; Vecchi et al. 2008). There are also good physical reasons to expect relative SST to be the more important quantity for TC activity, as was the case for mean precipitation, discussed above (Sobel et al. 2002; Vecchi and Soden 2007b; Swanson 2008). This is true for the the north Atlantic in particular. Recent increases in TC activity have been simultaneous with SST warming there (Emanuel 2005, 2007), but the more important fact may be that the tropical north Atlantic SST has increased more than the northern hemispheric average in this period.

If the absolute value of SST were considered the primary variable controlling TC activity, one would expect dramatic increases in TC activity as the climate warms. On the other hand, the picture is very different if one considers relative SST to be the more relevant variable. There is no reason to expect that future changes in relative SST will be anywhere near as large as changes in absolute SST. Future SST patterns are projected to be broadly similar to those today (with changes in spatial structure that are significant, but still small compared to the mean change, as can be seen from Fig. 12), except warmer. If one were to assume that statistical relationships between relative SST and TC activity from the present will continue to hold in the future, one would then expect relatively little change in TC activity, as shown in Fig. 15 (Vecchi and Soden 2007b; Vecchi et al. 2008).

Other environmental factors besides SST also play a role in controlling TC activity. One important one is the vertical wind shear, (the difference in the winds at low and high levels in the atmosphere). Future climate projections with the CMIP3 

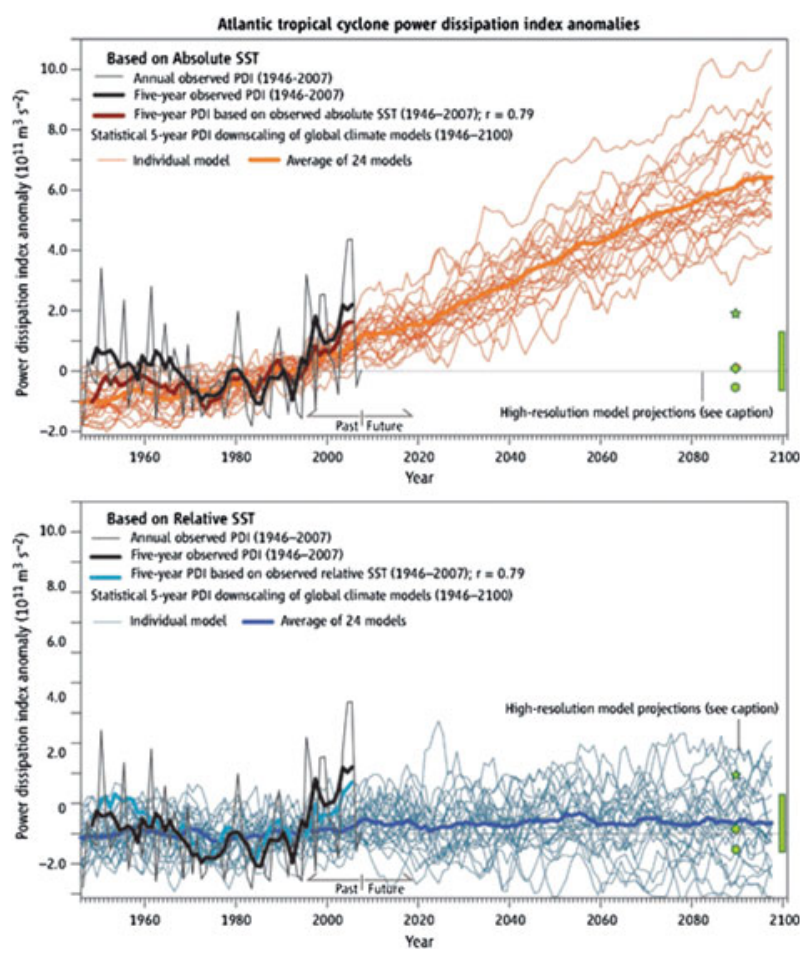

Fig. 15 Past and extrapolated changes in Atlantic hurricane activity. Observed anomalies in power dissipation index (PDI; an integrated measure of tropical cyclone activity that combines the number, intensity and duration of all storms each year) are regressed onto observed absolute (top) and relative (bottom) Atlantic SST over the period from 1946 to 2007, and these regression models are used to estimate PDI from output of global climate models for historical and future conditions. Anomalies are shown relative to the 1981 to 2000 average. The green bar denotes the approximate range of PDI anomaly predicted by calculations using another method combining statistical and dynamical methods, and the green dots denote the approximate values suggested by high-resolution dynamical models. SST indices are computed over the region $70^{\circ} \mathrm{W}-20^{\circ} \mathrm{W}, 7.5^{\circ} \mathrm{N}-22.5^{\circ} \mathrm{N}$, and the zero-line indicates the average over the period from 1981 to 2000. Figure from Vecchi et al. (2008)

models robustly indicate increases in vertical shear in much of the North Atlantic (Vecchi and Soden 2007a). All else equal, this would tend to reduce TC activity.

\subsubsection{New modeling evidence}

As available computing power has increased, models have improved, and new simulation strategies have been developed, rapid new progress has been made in the last few years (particularly since 2005, when Katrina occurred simultaneously with the publication of two influential studies indicating climatically-driven increases). Several new models have resolutions sufficiently high to represent TCs with reasonable fidelity-representing to some degree the eyes and other key structural features of TCs that cannot be captured by the low-resolution models used for IPCC AR4-while still representing global or at least large regional domains for long enough time periods that the large-scale climate is also organically simulated. Another new approach involves sophisticated "downscaling" methods which take 
information about the large-scale climate from low-resolution global climate models and use it as input for higher-resolution simulations of tropical cyclones to produce projections incorporating advantages of both elements.

Results from studies with both of these new methodologies show considerable diversity, but also an emerging consensus on the broad outlines of the changes in global TC activity that are expected in the warming climate. On average across the globe, assuming global climate changes within the range deemed most likely, the average intensity of tropical cyclones is expected to increase by $2-11 \%$ while the frequency of TC occurrence is expected to decrease by 6-34\% (Knutson et al. 2010). This projected decrease in frequency of all storms (from tropical storm up to category 5 hurricane strength) is not comforting, because the frequency of the most intense storms in particular is projected to increase. The most intense storms produce by far the greatest damage.

These projections are considerably more robust than those of just a few years ago, but they apply only to global average TC activity. We are not able to make projections with any confidence for individual regions such as the North Atlantic: when applied to individual regions, the available methodologies give results which vary too widely. Similarly, we cannot make with confidence any statements about changes in other aspects of tropical cyclone activity, such as genesis location, duration, and tracks.

\section{Sea level}

Worldwide, sea level rise is driven by processes occurring in the ocean and by transfer of water currently on land into the oceans (IPCC 2007). The two specific processes that contribute most are thermal expansion of ocean water and melting of land ice. ${ }^{6}$ Because seawater density depends on temperature, with warmer water having lower density, water in the ocean basins will expand as global mean temperature increases. The amount of expansion varies with location because warmer water expands more per unit temperature increase than does colder water, and the temperature of the ocean currently varies greatly with both depth and geography. Nonetheless, the contribution to sea level rise from thermal expansion is both well-understood and relatively small. The much larger and less-constrained contribution is the addition of water to the ocean from melting ice sheets and glaciers on land. Presently, the large ice sheets contain a total sea level equivalent of approximately $70 \mathrm{~m}$ (Bamber et al. 2007), meaning that sea level would rise by that much if the large ice sheets were to melt completely. While complete melting of all land ice is unlikely in the near future, this number gives a sense of the magnitude of the potential problem in the very long term.

The rate at which land ice is lost to the oceans ultimately depends on temperature, but not in a simple or obvious way. Simple melting of the ice on land is only one factor; the greater one is the possibility for large portions of marine-based ice sheets (ice resting on land whose base is below sea level but with a surface above sea level)

\footnotetext{
${ }^{6}$ Melting of sea ice-ice currently floating on the surface of the ocean-does not increase sea level, because the floating ice already displaces its weight in liquid water by Archimedes' principle, and that weight does not change when the ice melts.
} 
to become unstable and retreat rapidly (Schoof 2007). Globally averaged sea level rises by an amount of water equal to the volume of ice above an equivalent sea level. However, meltwater from rapid retreats is not distributed equally across the globe. Large changes in ice volume in Antarctica, for example, yield sea level changes 15$30 \%$ higher than the global average for the Gulf of Mexico and Caribbean (Mitrovica et al. 2009). The likelihood that a collapse will happen for any given ice sheet depends on ice sheet surface snow accumulation rates, magnitude of sea level rise to date, ocean temperature along a marine margin of an ice sheet, and both ice sheet configuration and sub-ice topography. The first three of these processes are linked intimately to temperature. Large scale ice sheet models that incorporate these features show tendency for rapid retreat (Pollard and DeConto 2009). However, at present no climate models incorporate these processes.

New semi-empirical approaches provide an alternative way for climate models to estimate sea level rise. These are based on the idea that the rate of sea level rise is proportional to the amount of global warming - the warmer it gets, the faster ice melts-and they use past sea level and temperature data to quantify this effect. Extrapolating into the future, these models suggest global sea level rises of about one meter by 2100 under the A1B scenario, about three times that projected by IPCC models (a 21-48 cm range for the same scenario; IPCC 2007; Vermeer and Rahmstorf 2009; Horton et al. 2008; Grinsted et al. 2009; Jevrejeva et al. 2010; summarized in Rahmstorf 2010). Yet, while these models take into account contributions from land ice of the kind recently observed, they still do not directly include the possibility of the non-linear ice dynamics described above producing extreme future changes in sea level.

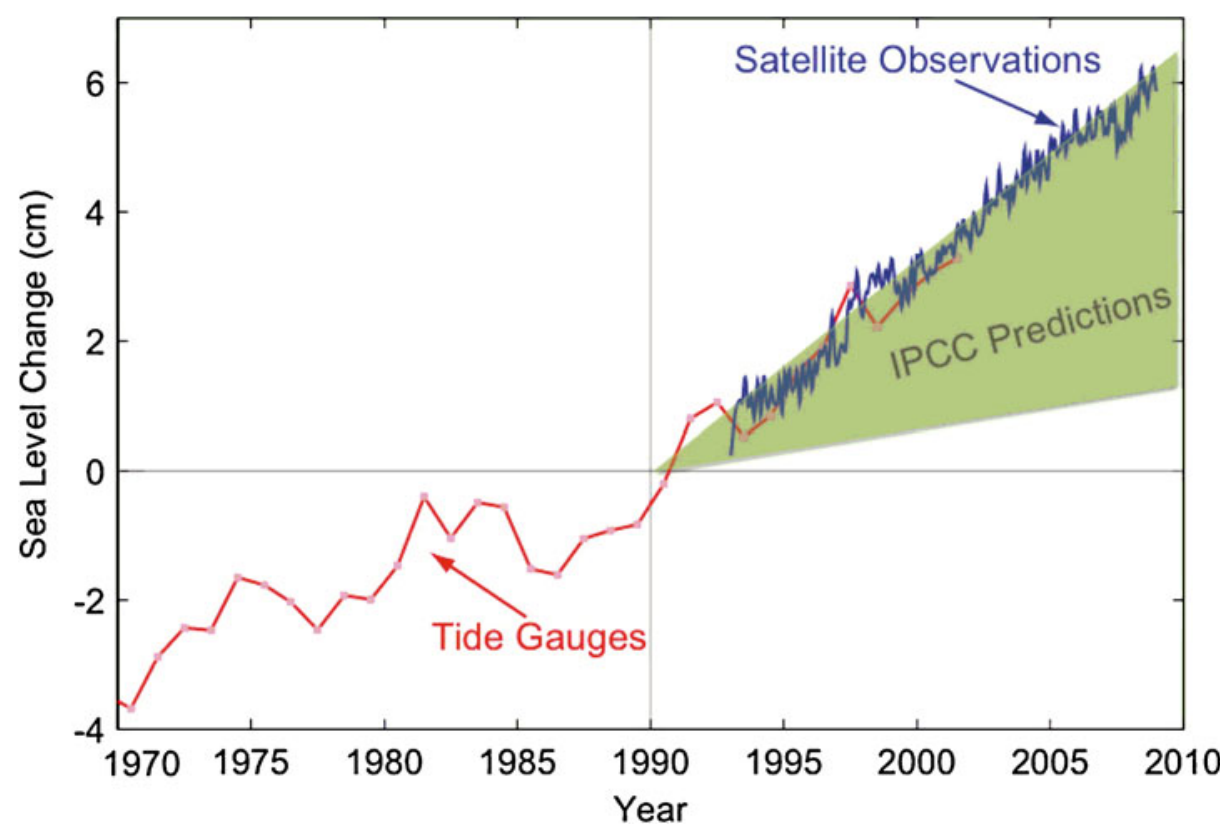

Fig. 16 Sea level change during 1970-2010. The tide gauge data are indicated in red (Church and White 2006) and satellite data in blue (Cazenave et al. 2009). The grey band shows the projections of the IPCC Third Assessment report (IPCC 2001) for comparison. Figure from Allison et al. (2009) 
The average rate of sea level rise over the 20th century was $1.7 \pm 0.3 \mathrm{~mm} \mathrm{yr}^{-1}$ from analysis of tide-gauge data (Church and White 2006). The rate has increased in recent years, however. From 1993 to 2003, the average rate of sea level rise was approximately $3.1 \mathrm{~mm} \mathrm{yr}^{-1}$ with approximately half that rate coming from thermal expansion (IPCC 2007, Chapter 5). Sea level is presently rising at a rate of 3.4$3.5 \mathrm{~mm} \mathrm{yr}^{-1}$ based on satellite-based sea-surface altimetry, tide gauges, and global gravity measurements (Fig. 16, Cazenave et al. 2009; Prandi et al. 2009). Since 2003, contributions from thermal expansion have reached a plateau and acceleration of sea level rise has increased as water is moved from storage in land ice to the ocean (Cazenave et al. 2009).

Information about the dependence of sea level on climate can be gained by studying evidence of sea level changes associated with fluctuations in climate in the distant past, especially the cycles of ice ages and deglaciations of the late Pleistocene and Holocene (roughly, the last million years). A recent compilation of rates of sea level rise for the northern Gulf of Mexico region gives rates over for the past four millenia as $0.4-0.6 \mathrm{~mm} \mathrm{yr}^{-1}$ (Milliken et al. 2008). From 4,000 to 7,000 years before the present time (BP), this rate was about $1.4 \mathrm{~mm} \mathrm{yr}^{-1}$, and for 7,000-10,000 $\mathrm{yr} \mathrm{BP}$, the rate of sea level rise was $4.2 \mathrm{~mm} \mathrm{yr}^{-1}$. Data from other areas of the Gulf of Mexico show much the same rates (Milliken et al. 2008) and these rates correspond reasonably well to the IPCC synthesis for the same time period (IPCC 2007). During the most recent highstand, approximately 115,000-125,000 years BP, sea level was 3-8 m higher than present (Blanchon et al. 2009; Kopp et al. 2009). Rates of sea-level rise entering this time period could have been as high as $36 \mathrm{~mm} \mathrm{yr}^{-1}$ for brief episodes (Blanchon et al. 2009; Waelbroeck et al. 2002), but were likely near $5 \mathrm{~mm} \mathrm{yr}^{-1}$ (Kopp et al. 2009).

Within their sea-level curves, Milliken et al. (2008) note large jumps above the average rate during the period 7,000-10,000 years BP that account for as much as $4 \mathrm{~m}$ of sea level rise. While there is no direct evidence, these jumps are consistent

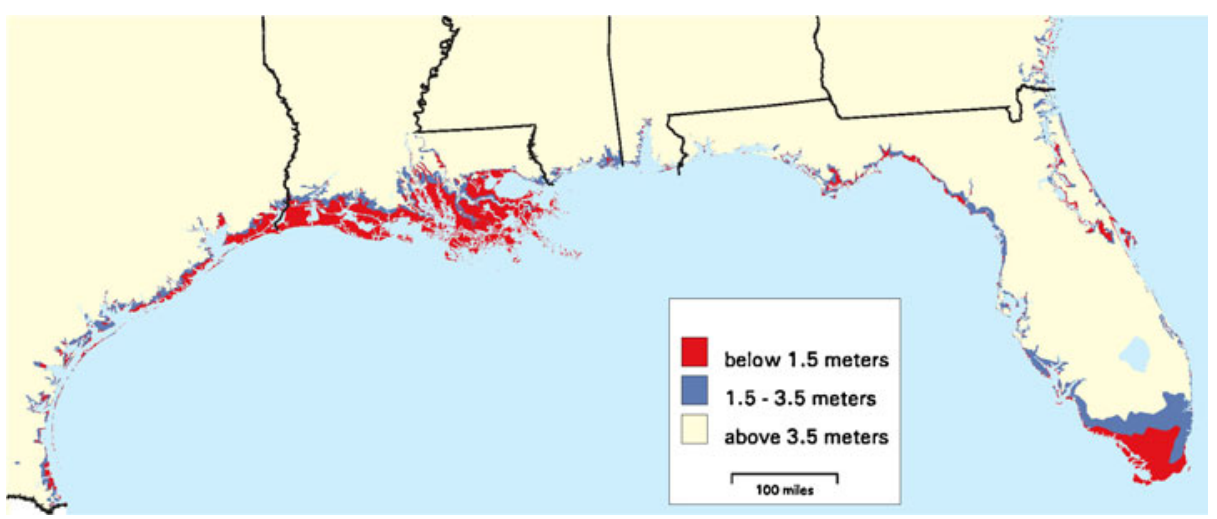

Fig. 17 Lands vulnerable to sea level rise. Regions shown in red are some of the areas that could be flooded at high tide if global warming causes sea level to rise $60 \mathrm{~cm}$ ( $2 \mathrm{ft}$ ) by 2100 . The indicated areas account not only for the effects of global warming, but also for other effects such as tidal variations and land subsidence. This figure and the details about how it was produced were originally published in Titus and Richman (2001) and are available from the EPA website: http://epa.gov/climatechange/effects/coastal/slrmaps.html 
with episodic deglaciation of either the remaining and now gone Laurentide Ice Sheet (the one which covered much of North America in the last ice age) or regions of the modern ice Sheets (Greenland, West Antarctica, East Antarctica). Because modern sea-level rise is now dominated by land ice loss, it is possible that similar rapid increases in sea level could occur in the future. Presently, outlets of Greenland and Antarctica in contact with warm ocean water are losing mass at extremely high rates (e.g., Pritchard et al. 2009; Rignot et al. 2008; Rignot and Kanagaratnam 2006). For sea level to inundate low lying areas of the Caribbean or Gulf coast, loss of mass from only one of a few sensitive basins in an ice sheet would be necessary, such as Pine Island Glacier in West Antarctica (Wingham et al. 2009). Indeed, the US Gulf coast and Florida, for example, have large areas no more than a meter or two above sea level which are already considered at risk of being flooded even for a relatively low sea level rise of $60 \mathrm{~cm}$ by 2100 (Fig. 17).

Besides direct inundation, sea level rise increases the risk to coastal areas from storm surge associated with tropical cyclones (even if the risk that a storm of a given intensity will strike does not increase). A large part of the damage due to hurricanes in many coastal areas results from storm surge, as the tropical cyclone winds blowing over a large surface of water bounded by a shallow basin cause the water to pile up and move onshore. The total water elevation that can occur at particular coastal location associated with tropical cyclones is due to the combined effects of storm surge, the astronomical tide, and breaking waves (Rao et al. 2008). The magnitude of the storm surge is dependent on the track, intensity, speed of movement and size of the hurricane, as well as coastal characteristics such as bathymetry (the depth and topography of the ocean floor) and the presence of rivers and deltas, and the level of the astronomical tide (Dube et al. 2004, 2009). These factors vary greatly from place to place and storm to storm. Nonetheless, in all cases increases in sea level raise the baseline to which storm surge adds to create the total water level experienced when a hurricane makes landfall or passes sufficiently close offshore. Thus coastal areas sufficiently high to avoid outright inundation will still be affected by sea level rise in that it will increase their risk of flooding due to storm surge.

\section{Conclusions}

We have described the changes in the climate of the Gulf of Mexico and Caribbean region that are expected to occur in the 21st century, assuming continued increases in greenhouse gas concentrations in the middle of the range considered in the Fourth Assessment Report of the Intergovernmental Panel on Climate Change (IPCC AR4). We have considered changes in temperature, precipitation, tropical cyclones (hurricanes) and sea level. We showed projections for temperature and precipitation based on the ensemble of climate model simulations performed for the IPCC AR4. Our discussions of tropical cyclones and sea level were based on surveys of the recent literature, including much that postdates IPCC AR4. The most certain and wellunderstood threat to the Gulf and Caribbean region from climate change is simply the increase in temperature. The region is already warm, but by the end of the 21st century, the typical summer will be warmer than any summer, even the most extreme, experienced in the past. The warming will be manifest not only on average but in the extremes (such as heat waves and warm nights) which will also be outside the experience of those living in the region today. 
Projected changes in precipitation are more varied geographically than those in temperature. The Caribbean is projected to become significantly drier. The reduction in precipitation, unlike the increase in temperature, is not expected to be so large as to make the mean season outside the range of conditions experienced in the past. However, water resources at a given time can be sensitive to rainfall over longer periods, so there can be serious consequences from multiple consecutive drier-thannormal years even if one such year would not be particularly harmful. Projected precipitation changes in the Gulf are small, but also highly uncertain.

The latest modeling evidence suggests that on a global basis, tropical cyclones will become less frequent, but more intense. The most intense storms, which are relatively infrequent at present but which do by far the most damage, are projected to become more frequent. Even on a global basis, these projected changes to the risk from tropical cyclones are considerably more uncertain than those in temperature or precipitation. For a single region such as the Gulf and Caribbean, the uncertainty is greater still. Some factors, such as projected changes in wind shear, may be expected to reduce the number and intensity of tropical cyclones in the region. Nonetheless, given the expected global tendency towards more of the most severe storms, there is little reason for complacency.

Sea level rise may ultimately be the greatest threat to the coasts and islands of the Gulf and Caribbean. The loss of even a small fraction of either the Greenland or Antarctica ice sheets would raise sea level enough to inundate significant areas of the region, and place larger areas at increased risk of storm surge from tropical cyclones (even if there were no change in the risk of tropical cyclone occurrence itself). The likelihood that such rapid ice loss and sea level rise will occur in the 21st century is very difficult to estimate, but there is evidence from the geologic record that they have occurred in the past in periods of warming. The probability becomes greater as the time horizon one considers increases, assuming continued warming. If greenhouse gas increases continue, the question over the long term becomes not whether sea level will rise greatly, but simply how soon it will do so.

Acknowledgements We are grateful to the researchers that produced Figs. 1, 12, 16, and 17 and to the publishers that granted permission to use them; to the modeling groups that provided climate simulations to the CMIP3 project; to the Program for Climate Model Diagnosis and Intercomparison (PCMDI) and the World Climate Research Programme's (WCRP's) Working Group on Coupled Modelling (WGCM) for their roles in making available the WCRP CMIP3 multi-model dataset (support of this dataset is provided by the Office of Science, U.S. Department of Energy); and to NARCCAP for the regional simulations (NARCCAP is funded by the National Science Foundation (NSF), the U.S. Department of Energy (DoE), the National Oceanic and Atmospheric Administration (NOAA), and the U.S. Environmental Protection Agency Office of Research and Development (EPA)).

This work was supported by the Earth Institute at Columbia University to inform policy-makers in the Gulf region in preparation for the United Nations Cancun Climate Summit.

\section{References}

Allison I, Bindoff N, Bindschadler R, Cox P, de Noblet N, England M, Francis J, Gruber N, Haywood A, Karoly D et al (2009) The Copenhagen Diagnosis, 2009: updating the world on the latest climate science. The University of New South Wales Climate Change Research Centre (CCRC), Sydney, Australia, p 60 
Bamber JL, Alley RB, Joughin I (2007) Rapid response of modern day ice sheets to external forcing. Earth Planet Sci Lett 257:1-13. doi:10.1016/j.epsl.2007.03.005

Battisti DS, Naylor (2009) Historical warnings of future food insecurity with unprecedented seasonal heat. Science 323. doi:10.1126/science.1164363

Blanchon P, Eisenhauer A, Fietzke J, Liebetrau V (2009) Rapid sea-level rise and reef back-stepping at the close of the last interglacial highstand. Nature 458:881-885. doi:10.1038/nature07933

Bueno R, Herzfeld C, Stanton E, Ackerman F (2008) The Caribbean and climate change: the costs of inaction. Tech. rep., Stockholm Environment Institute-US Center, Global Development and Environment Institute, Tufts University, Somerville, MA

Cazenave A, Dominh K, Guinehut S, Berthier E, Llovel W, Ramillien G, Ablain M, Larnicol G (2009) Sea level budget over 2003-2008: a reevaluation from GRACE space gravimetry, satellite altimetry and Argo. Global Planet Change 65(1-2):83-88. doi:10.1016/j.gloplacha.2008.10.004

Chang EK, Guo MY (2007) Is the number of north atlantic tropical cyclones significantly underestimated prior to the availability of satellite observations? Geophys Res Lett 34:L14,801

Church JA, White NJ (2006) A 20th century acceleration in global sea-level change. Geophys Res Lett 33:L01602. doi:10.1029/2005GL024826

Diffenbaugh N, Ashfaq M (2010) Intensification of hot extremes in the united states. Geophys Res Lett 37:L15701. doi:10.1029/2010GL043888

DiNezio PN, Clement AC, Vecchi GA, Soden BJ (2009) Climate response of the equatorial pacific to global warming. J Climate 22:4873-4892

Dube SK, Chittibabu P, Sinha PC, Rao AD, Murty TS (2004) Numerical modelling of storm surge in the Head Bay of Bengal using location specific model. Nat Hazards 31:437-453. doi:10.1023/B:NHAZ.0000023361.94609.4a

Dube SK, Jain I, Rao AD, Murty TS (2009) Storm surge modelling for the Bay of Bengal and Arabian Sea. Nat Hazards 51:3-27. doi:10.1007/s11069-009-9397-9

Elsner JB, Jagger TH, Dickinson M, Rowe D (2008) Improving multiseason forecasts of North Atlantic hurricane activity. J Climate 21:1209-1219

Emanuel K (2005) Increasing destructiveness of tropical cyclones over the past 30 years. Nature 436:686-688. doi:10.1038/nature03906

Emanuel K (2007) Environmental factors affecting tropical cyclone power dissipation. J Climate 20:5497-5509

Emanuel KA (1987) The dependence of hurricane intensity on climate. Nature 326:483-485

Evan AT, Vimont DJ, Heidinger AK, nand R Bennartz JPK (2009) The role of aerosols in the evolution of tropical North Atlantic Ocean temperature anomalies. Science 324:778781

Goldenberg SB, Landsea CW, Mestas-Nuñez AM, Gray WM (2001) The recent increase in Atlantic hurricane activity: causes and implications. Science 293:474-479

Gray WM (1979) Hurricanes: their formation, structure and likely role in the tropical circulation. In: Meteorology over the tropical oceans. Royal Meteorological Society, pp 155-218

Grinsted A, Moore JC, Jefrejeva S (2009) Reconstructing sea level from paleo and projected temperatures 200 to 2100 AD. Clim Dyn 34:461-472

Grinsted A, Moore JC, Jefrejeva S (2010) How will sea level respond to changes in natural and anthropogenic forcings by 2100? Geophys Res Lett 37. doi:10.1029/2010GL042947

Held IM, Soden BJ (2006) Robust responses of the hydrological cycle to global warming. J Climate 19:5686-5699

Holland GJ (1997) The maximum potential intensity of tropical cyclones. J Atmos Sci 54:25192541

Horton R, Herweijer C, Rosenzweig C, Liu J, Gornitz V, Ruane AC (2008) Sea level rise projections for current generation CGCMS based on the semi-empirical method. Geophys Res Lett 35. doi:10.1029/2007GL032.486

IPCC (2001) Climate change 2001: the scientific basis. Contribution of working group I to the third assessment report of the Intergovernmental Panel on Climate Change. Cambridge University Press, Cambridge

IPCC (2007) Climate change 2007: the physical science basis. Contribution of working group I to the fourth assessment report of the IPCC. Cambridge University Press, Cambridge

Karl TR, Melillo JM, Peterson TC, Hassol SJ (2009) Global climate change impacts in the United States. Cambridge University Press, Cambridge

Kharin V, Zwiers F, Zhang X, Hegerl G (2007) Changes in temperature and precipitation extremes in the IPCC ensemble of global coupled model simulations. J Climate 20(8):1419-1444. doi:10.1175/JCLI4066.1 
Knutson TR, McBride J, Chan J, Emanuel KA, Holland G, Landsea C, Held I, Kossin J, Srivastava AK, Sugi M (2010) Tropical cyclones and climate change. Nature Geoscience 3:157163. doi:10.1038/ngeo779

Kopp R, Simons F, Mitrovica J, Maloof A, Oppenheimer M (2009) Probabilistic assessment of sea level during the last interglacial stage. Nature 462(7275):863-867

Kossin JP, Knapp KR, Vimont DJ, Murnane RJ, Harper BA (2007) A globally consistent reanalysis of hurricane variability and trends. Geophys Res Lett 34:L04,815

Landsea CW (2005) Hurricanes and global warming. Nature 438:E11-E13. doi:10.1038/nature04477

Landsea CW (2007) Counting atlantic tropical cyclones back to 1900. EOS Trans AGU 88(18). doi:10.1029/2007EO180001

Landsea CW, Harper BA, Horau K, Knaff JA (2006) Can we detect trends in extreme tropical cyclones? Science 313:452-454. doi:10.1126/science.1128448

Landsea CW, Vecchi GA, Bengtsson L, Knutson TR (2010) Impact of duration thresholds on atlantic tropical cyclone counts. J Climate. doi:10.1175/2009JCLI3034.1

Leloup J, Clement A (2009) Why is there a minimum in projected warming in the tropical North Atlantic Ocean? Geophys Res Lett 36. doi:10.1029/2009GL038609

Mann ME, Emanuel KA (2006) Atlantic hurricane trends linked to climate change. EOS 87:233, 238, 241

Mann ME, Sabbatelli TA, Neu U (2007) Evidence for a modest undercount bias in early historical Atlantic tropical cyclone counts. Geophys Res Lett 36:L22,707

Meehl G, Covey C, Delworth T, Latif M, McAvaney B, Mitchell J, Stouffer R, Taylor K (2007) The WCRP CMIP3 multimodel dataset: a new era in climate change research. Bull Am Meteorol Soc 88:1383-1394

Milliken KT, Anderson JB, Rodriguez AB (2008) A new composite Holocene sea-level curve for the northern Gulf of Mexico. In: Anderson JB, Rodriguez AB (eds) Response of upper Gulf Coast estuaries to Holocene climate change and sea-level rise. Geological Society of America, Boulder, CO, special paper 443, pp 1-11. doi:10.1130/2008.2443(01)

Mitrovica J, Gomez N, Clark P (2009) The sea-level fingerprint of West Antarctic collapse. Science 323(5915):753

Philander SGH (1990) El Niño, La Niña and the southern oscillation. Academic, New York

Pollard D, DeConto R (2009) Modelling West Antarctic ice sheet growth and collapse through the past five million years. Nature 458(7236):329-332

Prandi P, Cazenave A, Becker M (2009) Is coastal mean sea level rising faster than the global mean? A comparison between tide gauges and satellite altimetry over 1993-2007. Geophys Res Lett 36:L05602. doi:10.1029/2008GL036564

Pritchard HD, Arthern RJ, Vaughan DG, Edwards LA (2009) Extensive dynamic thinning on the margins of the Greenland and Antarctic ice sheets. Nature 461(7266):971-975. doi:10.1038/ nature08471

Rahmstorf S (2010) A new view on sea level rise. Nature 4. doi:10.1038/climate.2010.29

Rao AD, Jain I, Murthy MVR, Murty TS, Dube SK (2008) Impact of cyclonic wind field on interaction of surge?wave computations using finite-element and finite-difference models. Nat Hazards 49:225-239. doi:10.1007/s11069-008-9284-9

Rauscher S, Giorgi F, Diffenbaugh N, Seth A (2008) Extension and Intensification of the MesoAmerican mid-summer drought in the twenty-first century. Clim Dyn 31:551-571. doi:10.1007/ s00382-007-0359-1

Rauscher SA, Kucharski F, Enfield DB (2010) The role of regional sst warming variations in the drying of meso-america in future climate projections*. J Climate 24(7):2003-2016. doi:10.1175/2010JCLI3536.1

Rignot E, Kanagaratnam P (2006) Changes in the velocity structure of the Greenland Ice Sheet. Science 311(5763):986-990. doi:10.1126/science.1121381

Rignot E, Bamber JL, Broeke MRVD, Davis C, Li YH, Berg WJVD, Meijgaard EV (2008) Recent Antarctic ice mass loss from radar interferometry and regional climate modelling. Nature Geoscience 1(2):106-110. doi:10.1038/ngeo102

Sarachik ES, Cane MA (2010) The El Niño-southern oscillation phenomenon. Cambridge University Press, Cambridge

Schoof C (2007) Ice sheet grounding line dynamics: steady states, stability, and hysteresis. J Geophys Res 112(F3):1-19

Sobel AH (2007) Simple models of ensemble-averaged tropical precipitation and surface wind. In: Schneider T, Sobel AH (eds) The global circulation of the atmosphere. Princeton University Press, Princeton 
Sobel AH, Held IM, Bretherton CS (2002) The ENSO signal in tropical tropospheric temperature. J Climate 15:2702-2706

Swanson KL (2008) Nonlocality of atlantic tropical cyclone intensity. Geochem Geophys Geosyst 9:Q04V01

Ting M, Kushnir Y, Seager R, Li C (2009) Forced and natural 20th century SST trends in the north atlantic. J Climate 22:1469-1481

Titus JG, Richman C (2001) Maps of lands vulnerable to sea level rise: modeled elevations along the US Atlantic and Gulf Coasts. Clim Res 18:205-228

Vecchi GA, Knutson TR (2008) On estimates of historical north atlantic tropical cyclone activity. J Climate 21:3580-3600. doi:10.1175/2008JCLI2178.1

Vecchi GA, Soden BJ (2007a) Effect of remote sea surface temperature change on tropical cyclone potential intensity. Nature 450:1066-1070

Vecchi GA, Soden BJ (2007b) Global warming and the weakening of the tropical circulation. J Climate 20:4316-4340

Vecchi GA, Soden BJ, Wittenberg AT, Held IM, Leetmaa A, Harrison MJ (2006) Weakening of tropical pacific atmospheric circulation due to anthropogenic forcing. Nature 441. doi:10.1038/nature04744

Vecchi GA, Swanson KL, Soden BJ (2008) Whither hurricane activity? Science 322:687. doi:10.1126/science.1164396

Vermeer M, Rahmstorf S (2009) Global sea level linked to global temperature. Proc Natl Acad Sci 106:21527-21532

Waelbroeck C, Labeyrie L, Michel E, Duplessy JC, McManus JF, Lambeck K, Balbon E, Labracherie M (2002) Sea-level and deep water temperature changes derived from benthic foraminifera isotopic records. Quat Sci Rev 21:295-305

Webster PJ, Holland GJ, Curry JA, Chang HR (2005) Changes in tropical cyclone number, duration, and intensity in a warming environment. Science 309:1844-1846. doi:10.1126/science.1116448

Wingham DJ, Wallis DW, Shepherd A (2009) Spatial and temporal evolution of Pine Island Glacier thinning. Geophys Res Lett 36:L17501. doi:10.1029/2009GL039126

Xie SP, Deser C, Vecchi GA, Ma J, Teng H, Wittenberg AT (2010) Global warming pattern formation: sea surface temperature and rainfall. J Climate, early online. doi:10.1175/2009JCLI3329.1 